\title{
Reconstitución física y cultural de la población tardía del cementerio Quitor 6 (San Pedro de Atacama)
}

M. Antonietta Costa ${ }^{1}$

\section{Introducción}

La delimitación temporal para la fase tardía de la Cultura San Pedro se había basado hasta el momento en el único fechado radiocarbónico disponible para esta zona: una tumba de Quitor 6 que arroja una antigüedad de 1050 DC (Núñez 1976). En cuanto al material cultural, éste se conocía parcialmente como contexto de algunas tumbas tardías de diferentes cementerios. El material osteológico también había sido poco examinado.

Esta debilidad en el conocimiento de la Fase Tardía nos motivó a buscar una mejor definición de ella, a través del estudio de un cementerio típicamente tardío. Se trata de saber, a la luz de análisis más refinados, cuáles son los indicadores antropofísicos $\mathrm{y}$ culturales de esta fase.

El cementerio Quitor 6 fue trabajado durante muchos años por el R. P. Gustavo Le Paige, siendo conocido como un sitio perteneciente a la Fase Media de la Cultura San Pedro. En 1983 se realizó una nueva excavación a cargo de Agustín Llagostera, patrocinada por la Dirección de Investigaciones y Extensión de la Universidad del Norte. En esa oportunidad se excavó el sector norte del cementerio, que se mantenía intacto, obteniéndose 42 tumbas con contextos tardíos.

El presente trabajo es un resumen de la Memoria para optar al título de Arqueólogo que presentamos a la Carrera de Arqueología de la Universidad del Norte; la fase de análisis en laboratorio fue también financiada por la Dirección de Investigaciones y Extensión de esa Casa de Estudios.

1 Instituto de Investigaciones Arqueológicas, Universidad del Norte, San Pedro de Atacama, CHILE.

\section{Ubicación y características culturales de Quitor 6}

Quitor 6 se encuentra en el oasis homónimo de San Pedro de Atacama (Figura 1); se presenta sobre una terraza aluvional de rodados que conforma los faldeos de la Cordillera de la Sal, al margen izquierdo del río San Pedro (Figura 2).

Se compone de 42 tumbas excavadas en forma de pozos circulares (Figura 3), directamente en el suelo compacto y conglomerado, en las cuales se encontraron 33 cuerpos de adultos y 14 de subadultos. Cinco de estos entierros eran dobles, conteniendo un adulto y un niño; en uno de estos casos se trataba de un hombre con el niño, y en los otros cinco, de una mujer con la criatura.

En 13 tumbas se verificó que la superficie presentaba estructuras de piedras dispuestas en círculo, al interior del cual podía haber otra piedra central y/o una vasija cerámica rota (Figura 4). En cinco de estas tumbas, a varios centímetros sobre la cabeza del individuo, se colocó una capa de vainas y semillas de algarrobo, cubriendo todo el diámetro del pozo. En dos de ellas, además, aparecen esqueletos de cánidos a los pies del individuo. Estas tres características eran hasta ahora desconocidas para el sitio, siendo específicas de esta fase tardía (Figura 5).

Los cuerpos eran enterrados en posición sentada, flectados, preferentemente con los brazos cruzados sobre la pelvis. Todos se orientaban hacia el este.

Los ajuares funerarios se caracterizan por tres rasgos importantes: a) un reducido número de objetos por individuos; b) los objetos han sufrido una "miniaturización", con excepción de aquellos que, por funcionalidad, deben mantener dimensiones estandarizadas: arcos, flechas, etc.; c) hay un notorio desmejoramiento de la técnica de confección y ausencia casi completa de decoración en las piezas. La apariencia de las mismas es tosca o descuidada. Y en general las formas sufrieron simplificaciones. 


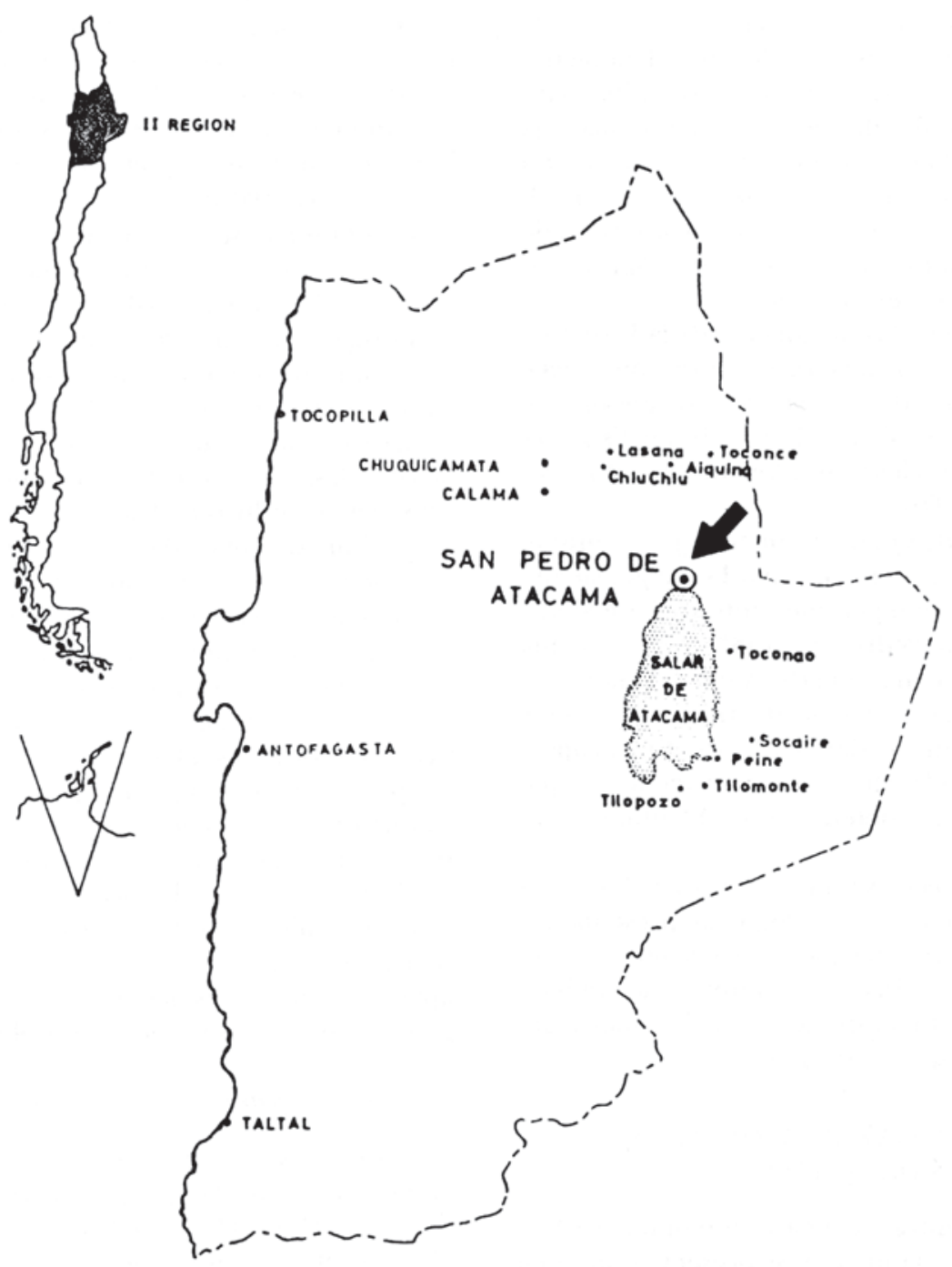

Figura 1. Ubicación de San Pedro de Atacama en la II Región de Chile.

Cambios en el patrón de los enterratorios

Fue notorio el cambio observado en el patrón de enterramiento de este grupo, en relación a las gentes de la Fase II de la Cultura San Pedro, que ocuparon el sector más temprano del cementerio. Lo más evidente fue visualizado en las 13 tumbas con estructuras circulares de piedra en superficie, a que ya hicimos referencia. En los sectores centro y sur del cementerio no se encontró este tipo de estructura, y en los apuntes de Le Paige encontramos anotado que "no aparece indicación de tumbas por gruesas piedras" (Le Paige Ms). Otra diferencia la constituye la capa de algarrobo en un nivel superior a la cabeza del individuo, asociadas todas estas ocurrencias con la existencia de estructuras de piedras en superficie.

En dos de estas tumbas, además de las evidencias de camélidos, presentes en casi todos los enterratorios (pertenecientes a las dos fases), hay roedores, y aparecen además esqueletos de cánidos.

Se advierte también un cambio en la forma en que colocaban el cuerpo en la tumba: en los sectores más tempranos, el mismo quedaba en una posición 


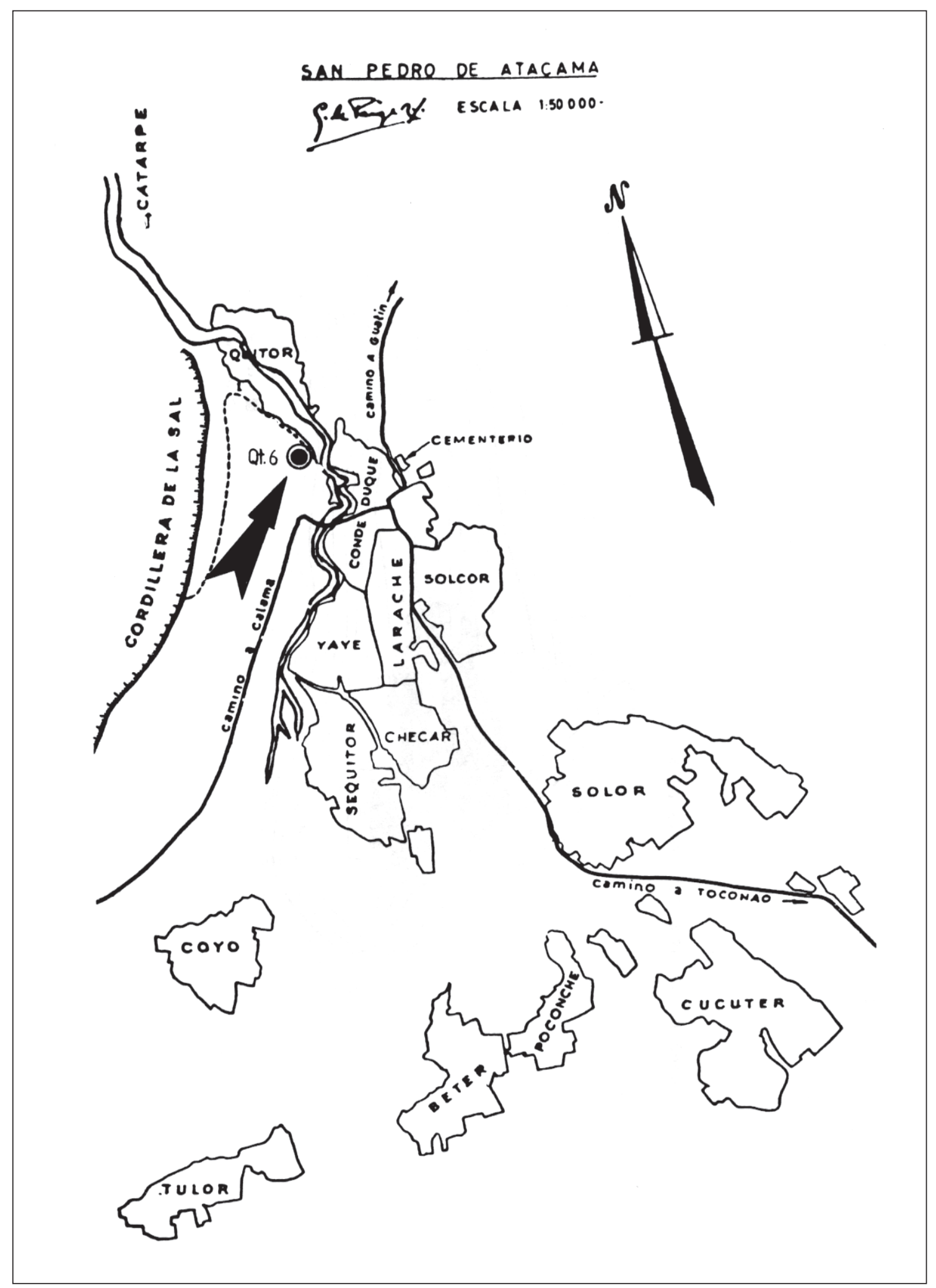

Figura 2. Ubicación de Quitor 6 en San Pedro de Atacama. Tomado de Le Paige (1964: 52). 


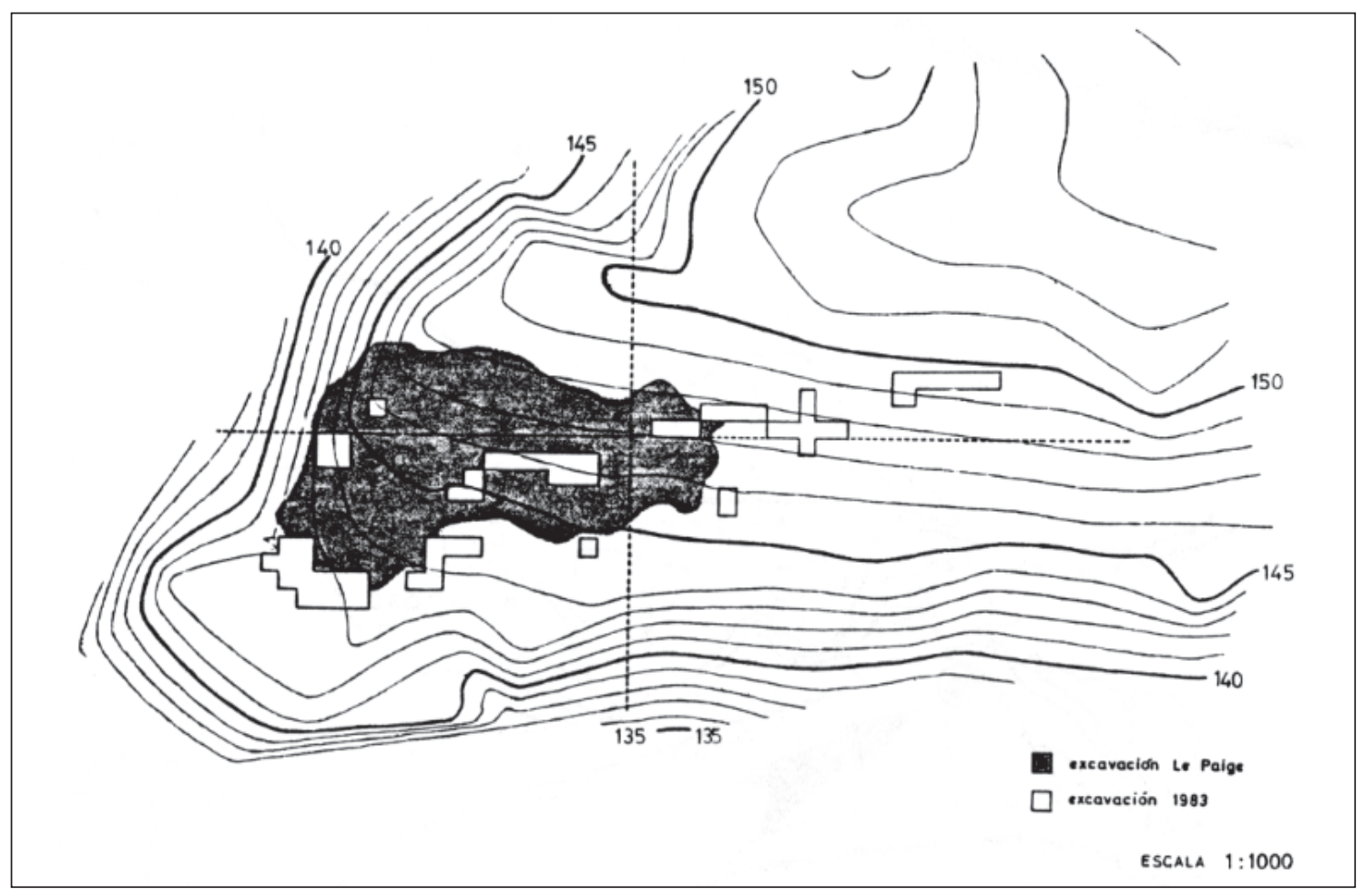

Figura 3. Plano de Quitor 6.

netamente "sentada", apoyado sobre la pelvis, y la columna en una posición muy próxima a la verticalidad. En el sector tardío, aunque se mantiene la posición sentada, se verifica una tendencia a que el cuerpo se coloque recostado sobre la espalda, ligeramente cargado hacia uno de los lados.

En cuanto al material cultural, la ofrenda funeraria se reduce fuertemente en relación a la fase anterior; es escasa y hasta inexistente en algunos casos. Las ofrendas en tumbas infantiles suelen ser, si no más numerosas, por lo menos más jerarquizadas que en el caso de los adultos. La cerámica, antes abundante y bien trabajada (evidentemente mortuoria), ahora presenta formas más utilitarias, en muchos casos miniaturizadas. La cestería reemplaza muchas veces a la cerámica y es también de pequeño tamaño, casi sin decoración, contrastando con las grandes formas decoradas de la Fase II.

Los escasos vestigios de textiles demuestran una factura burda, de hilos gruesos y muy poca decoración. Los pocos instrumentos que integran el complejo de inhalación de alucinógenos no podrían ser más sencillos, en contraposición a los bien elaborados artefactos de la fase anterior.

\section{Cronología}

Se ha obtenido un juego de fechas absolutas para este sitio: tres por radiocarbono (Beta Analytic Inc.) y dos por termoluminiscencia (Laboratorio de Física de la Universidad Católica de Santiago) (Berenguer 1985). Las fechas se muestran en el Cuadro 1:

\begin{tabular}{|c|c|c|c|c|}
\hline $\mathbf{N}^{\circ}$ tumba & Edad 1240 $\pm \mathbf{7 0}$ DC & Laboratorio & Tipo muestra & Investigador \\
\hline 35 & $1240 \pm 70 \mathrm{DC}$ & Beta 11207 & Madera & M.A. Costa \\
35 & $1140 \pm 130 \mathrm{DC}$ & UC-TL-17 & Cerámica & J. Berenguer \\
36 & $920+70 \mathrm{DC}$ & Beta 11208 & Textiles & M.A. Costa \\
50 & $1060 \pm 180 \mathrm{DC}$ & Beta 9349 & Madera & M.A. Costa \\
54 & $840 \pm 70 \mathrm{DC}$ & UC-TL-18 & Cerámica & J. Berenguer \\
\hline
\end{tabular}

Cuadro 1. Fechas absolutas obtenidas para Quitor 6. 

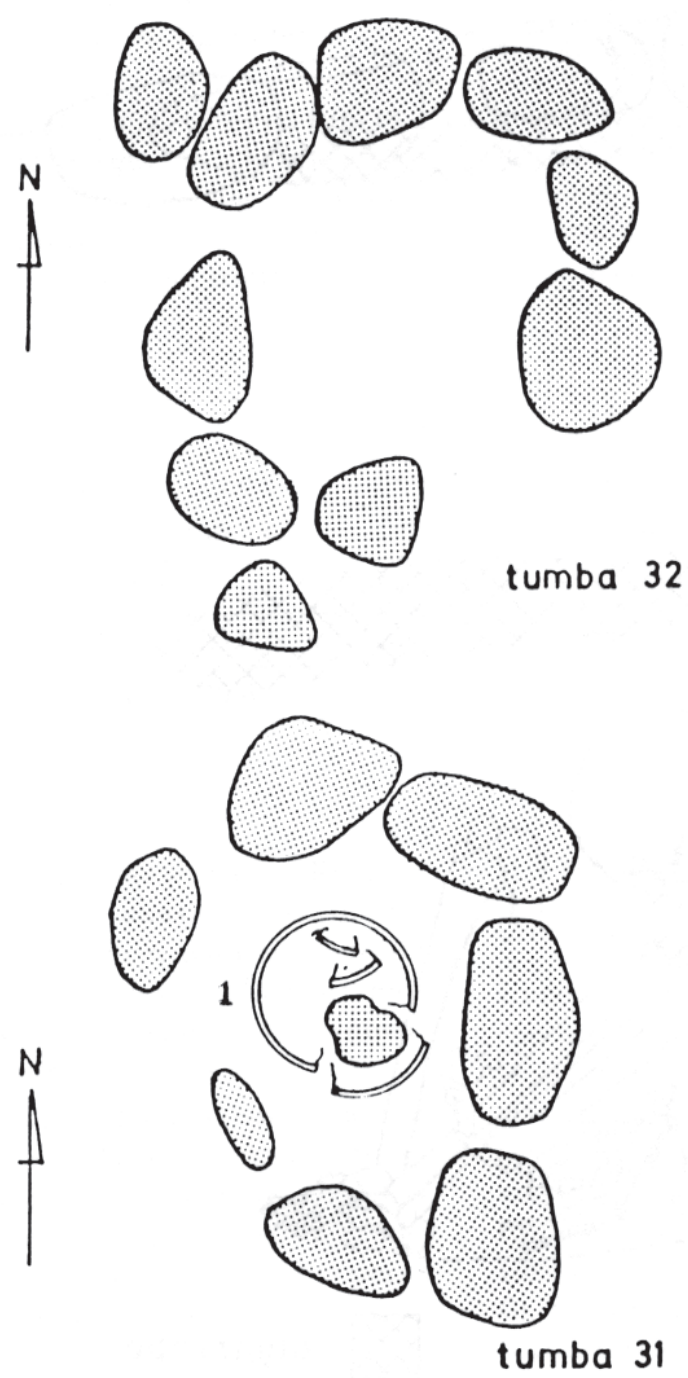

1 Ceramio

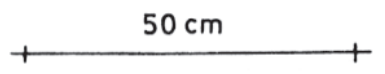

Figura 4. Planta de estructuras superficiales.

Para la tumba 35 tenemos una fecha por $\mathrm{RC}^{14} \mathrm{y}$ otra por TL. ${ }^{2}$ Entre ambas hay una diferencia de 100

2 Para esta tumba tenemos aún otra fecha de $1740 \pm 120$ AP (Beta 9350), que rechazamos por discrepar completamente de las demás, que consideramos correctas. años; si usamos el sigma positivo para el rango de variación estimado para la fecha por TL, acortamos esta diferencia. Creemos correcta una fecha terminal para el sitio, del orden de 1240 DC.

La tumba 54 presenta la fecha más temprana, con 840 DC. Basándose en la confrontación de fechados 


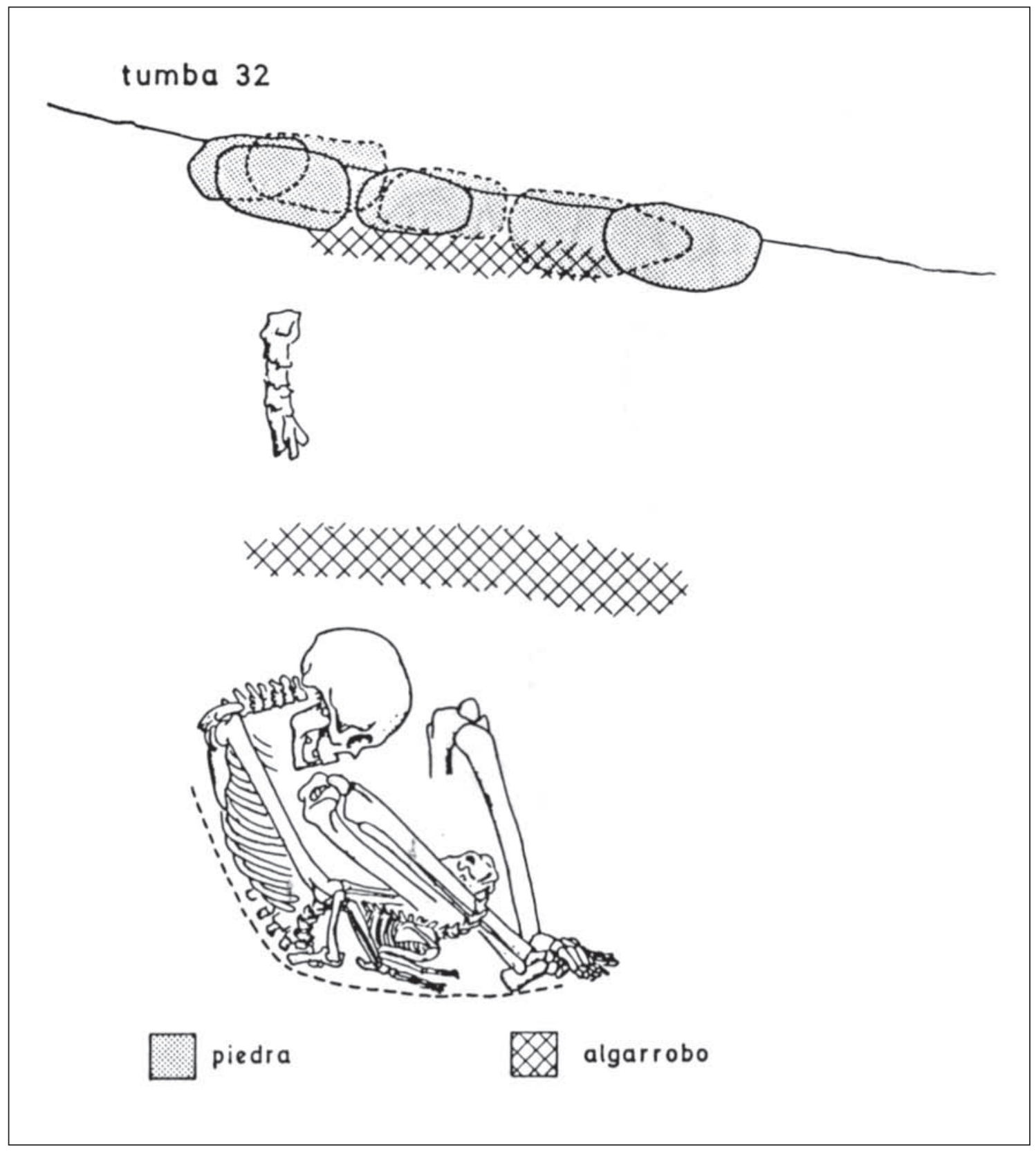

Figura 5. Tumba 32 de Quitor 6.

obtenidos por distintos métodos, creemos prudente adelantar los fechados por TL en 100 años; esto nos estaría dando una fecha inicial para el sitio a los 940 DC, coherente con las demás.

Suponemos entonces, que este sector del cementerio Quitor 6 fue utilizado durante un lapso de 300 años, entre 940 y 1240 DC.

\section{Material cultural}

Cerámica

La cerámica está presente en un 38\% de las tumbas, con un total de 27 piezas. El tipo más popular es el Dupont (Núñez 1965), con el 50\% de las ocurrencias. El tipo Rojo Violáceo alcanza el 27\% de los casos. 
En cuanto a las formas, la Forma I (escudilla abierta) aparece en el 50\% de las veces, y la Forma II (puco) aparece el $23.1 \%$ de los casos. Las demás formas aparecen una o dos veces solamente (Figura 6). Se podría considerar a la cerámica Dupont, con forma de escudilla abierta, como la más característica de la Fase Tardía de Quitor 6. Las dos únicas piezas decoradas del sitio son consideradas foráneas: una similar a las encontradas en La Isla (Humahuaca) y en sitios de la Puna del Noroeste Argentino (Forma VII), y otra Forma Foránea, posiblemente del sur de Bolivia (ver Figura 6).

Hay una cierta uniformidad en cuanto a las inclusiones de la pasta. Los granos tienden a ser grandes y no uniformes, variando entre 1 y $2 \mathrm{~mm}$ y siempre se trata de partículas angulosas. En todos los casos de cerámicas locales, la fractura es irregular y la textura va de laminar a compacta, con tendencia a laminar.

Solamente en dos casos la técnica de manufactura fue posiblemente la de ahuecamiento (digitado); en todos los demás, se usó el sistema de enrollamiento. La cocción, sea oxidante, sea reductora, en muchos casos es mal controlada, resultando así una cerámica manchada.

No se verifica en el sitio la vasija de doble cuerpo y engobe borravino, considerada típica de la Fase III de San Pedro (tal vez por lo reducido de la muestra).

\section{Calabazas}

Fueron encontrados 46 ejemplares, de los cuales cinco tienen decoración pirograbada, o en pintura negra aplicada poco prolijamente. Estuvieron presentes en $78.6 \%$ de las sepulturas.

\section{Cestería}

Solamente dos, de las 29 piezas encontradas, eran decoradas; una, usando fibras vegetales de color oscuro, combinadas con las de color natural; y la segunda con uso de lanas de colores. El 75.9\% de los recipientes fue trabajado con la técnica "en espiral" (coiled), en la variedad "cerrada" (close coil; Adovasio 1977) con densidades de medianas a altas, y que oscilan entre dos y seis vueltas por centímetro y entre dos y 13 puntadas por centímetro. La inclinación de la puntada es preferentemente de izquierda a derecha $(34.5 \%)$. Aparecen aun seis ejemplares de cestería twined, realizados en fibras vegetales, en la variedad diagonal twining (Adovasio 1977).
Las condiciones muy malas de conservación no permitieron el estudio acabado de formas; sólo pudimos identificar siete especímenes troncocónicos.

También encontramos la técnica que Adovasio (1977) llamada diagonal twining y que consiste en que las urdimbres son tomadas en pares por la trama, en forma alternada en cada vuelta del tramado, en relación a la vuelta anterior. También aparece aquí una variedad, que observamos en otros sitios de la zona, donde la trama está compuesta por cuatro cabos que funcionan como dos pares de trama; a cada vuelta, cada par se intercruza entremedio de urdimbres alternas, o sea, por debajo de dos y por encima de las dos siguientes; ello produce un efecto de "retorcido". En todos los casos la modalidad del tejido ha sido la "cerrada"; en ella, la urdimbre es totalmente cubierta por la trama. La torción de esta última es en "S". Encontramos solamente un fragmento de base, el que presenta 24 elementos de urdimbre que se cruzan al centro en grupos de seis, en un patrón de asterisco.

Es interesante observar el comportamiento de la cerámica y de las calabazas en relación al sexo de los individuos: las mujeres presentan los más altos porcentajes en relación a los hombres: $36.4 \%$ de mujeres con cerámica (27.3\% de hombres); $45.5 \%$ con cestería ( $27.3 \%$ de hombres). Pero la situación cambia en cuanto a las calabazas, ya que el porcentaje de hombres con estos objetos sube a $81.8 \%$ contra $72.7 \%$ de mujeres; es notorio además que los cinco ejemplares decorados se encontraban en tumbas masculinas e infantiles; aparentemente hay exclusión del sexo femenino relacionado con la decoración de calabazas en la fase tardía de Quitor 6.

\section{Madera}

Es la industria más numerosa y con el mejor nivel técnico dentro del material cultural del sitio, en un total de 75 objetos.

Cucharas: Son seis cucharas, cada una de las cuales constituye una forma diferente, que tratamos de asimilar a la tipología propuesta por Espoueys (1972-73) para las cucharas de madera de Arica. De la Familia I, Grupo B, aparecen los tipos B2 (Figura 7a), B3 (Figura 8e) y B4, esta última, con un tallado volumétrico tridimensional en la extremidad proximal, en forma de "boquilla" no funcional (Figura 7c). Para la familia II incorporamos el Grupo I a la tipología de Espoueys, que corresponde al mango de sección 


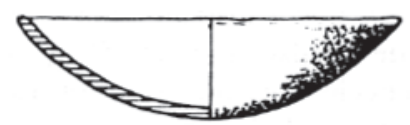

FORMA I

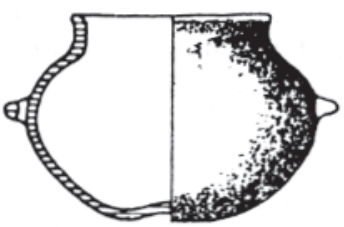

FORMA III
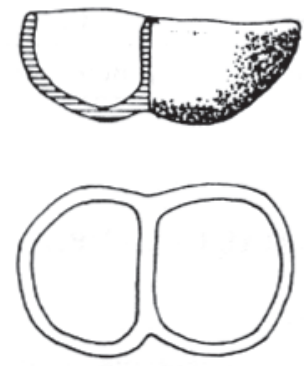

FORMA $v$
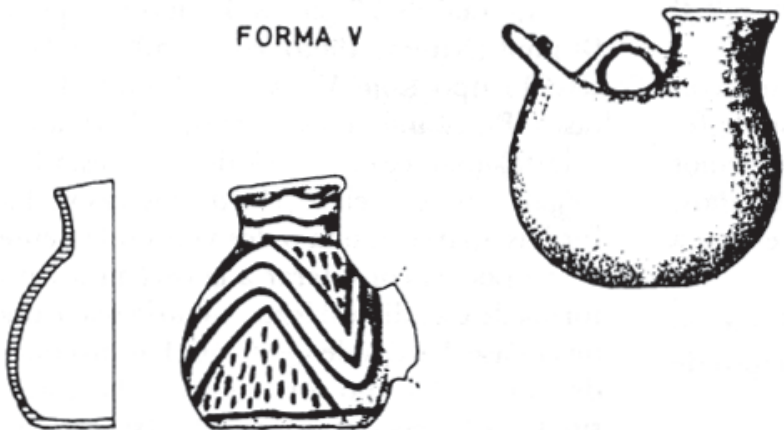

FORMA VII

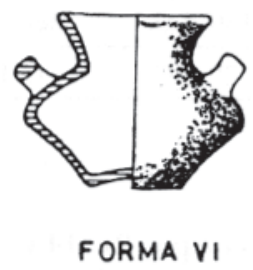

FORMA FORANEA

Figura 6. Formas de cerámica encontradas en Quitor 6. 
RECONSTITUCION FISICA Y CULTURAL DE LA POBLACION TARDIA DEL CEMENTERIO DE QUITOR $6 \ldots$
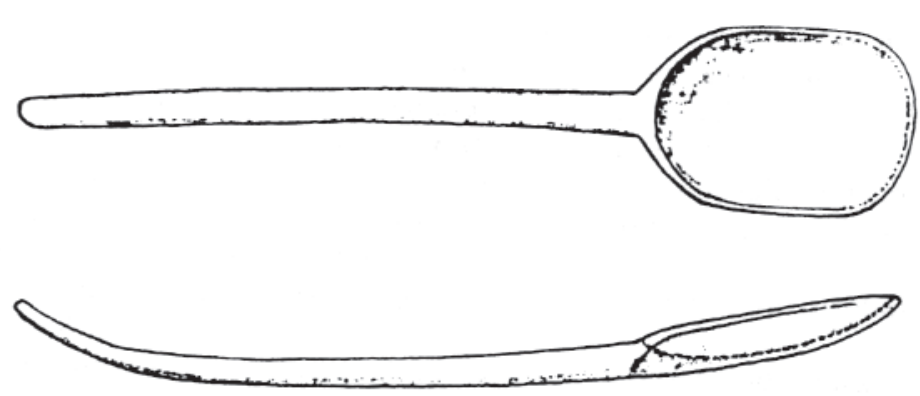

a
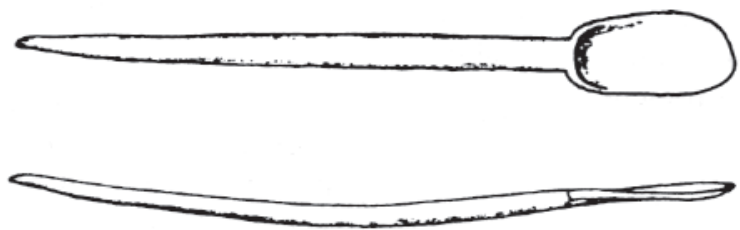

b
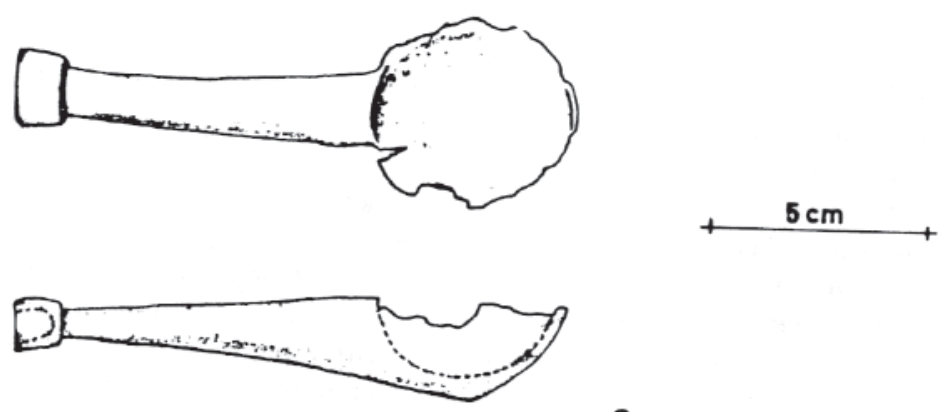

C
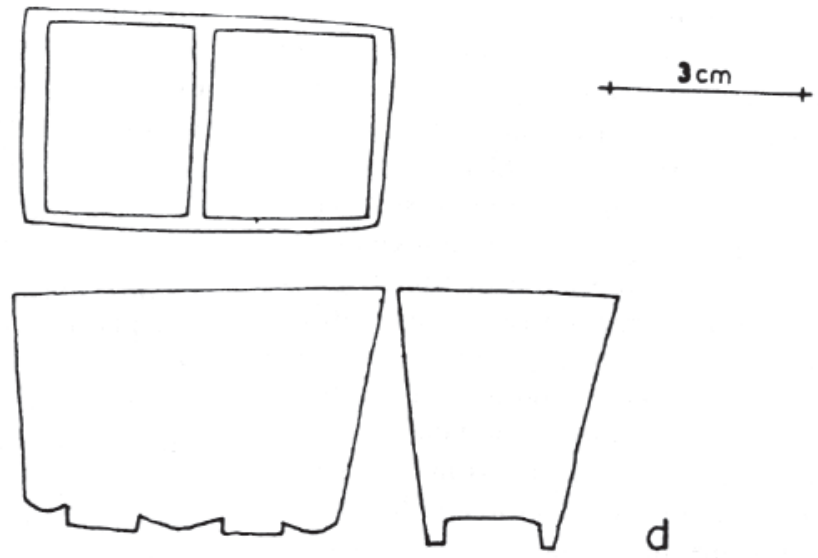

d

Figura 7. Objetos de madera encontrados en Quitor 6. 
circular, con un Tipo II. El tercio inferior del mango está decorado con un recorte a la redonda que se produce aproximadamente a cada centímetro, formándose así tres segmentos troncocónicos que, en conjunto, se asemejan a las patas de un coleóptero (Figura 8f). Finalmente, tenemos la Familia III, Grupo J (otro grupo que incorporamos a la tipología ya referida), con mango de sección rectangular, el Tipo J1 (Figura 7b). La sexta pieza se refiere a la pala de una cuchara a la que se eliminó el mango a través de un corte; queda como evidencia una pequeña proyección desbastada y lijada. Justamente al lado de esa proyección hay una zona carbonizada. Estas piezas fueron encontradas en dos tumbas de mujeres y en una masculina.

Pilones: Los dos pilones encontrados muestran decoración. El Tipo 1 presenta un motivo tallado, en forma de dos cuerpos troncocónicos superpuestos (Figura 8c). El tipo 2 (Figura 8b) es un ejemplar miniaturizado con la extremidad proximal recortada en un rectángulo planiforme, en el cual fueron talladas caras antropomorfas a ambos lados, en las que se insinuaron los ojos y la boca por medio de incisiones, y la nariz, por un tallado en relieve. Ambos fueron hallados en tumbas infantiles.

Tabletas para inhalar alucinógenos: Fue encontrada solamente una tableta rectangular, en una tumba masculina; el panel se conforma por un rebaje practicado cerca de los bordes, sin ninguna decoración. La acompañaba un fragmento de tubo para alucinógenos, que incluye la boquilla y parte del tubo; en su interior se encuentran dos espinas de cactáceas (Figura 9b, c).

Kero: Este objeto está decorado con un tallado en banda anillada en media caña y una figura zoomorfa erecta, de un saurio; la cabeza se asoma sobre el borde, las patas delanteras se apoyan sobre el mismo y el cuerpo se proyecta hacia abajo. Las patas traseras y la cola se encuentran sobre la banda anillada; la cola se dirige verticalmente hacia abajo. Este tipo coincide con lo descrito por Núñez (1963) para los kero del norte de Chile, en su Tipo II. Los elementos decorativos descritos por él se refieren a la fase incaica y difieren de este ejemplar en cuanto que la cola del saurio siempre se encuentra vuelta hacia la izquierda. La banda en media caña es, además, menos saliente y su sección es rectangular (Figura 9a).

Cajitas: Las cajitas comparten detalles diagnósticos descritos por Núñez (1964) para Quitor 1, Chiu Chiu y
Chiza, al parecer asociados con elementos tiwanacotas. Se definen como cajitas de doble compartimiento, rectangulares, base levantada por medio de pedestales que corren a lo largo de la pieza, con decoración recortada en motivos geométricos y las paredes inclinadas hacia afuera (Figura 7d).

Espátula: La confección de la espátula es típica y muy sencilla. Presenta desgaste por uso en el borde izquierdo de la extremidad activa (distal). Encontrada en entierro femenino.

Torteras: Se encontraron 15 torteras, en tumbas femeninas o de niños. Se dividen en dos grandes grupos: 1) de sección tabular y 2) de sección circular. Las primeras se subdividen en: a) sección tabuliforme rectangular; b) tabuliforme plano convexa; c) tabuliforme elipsoide (Figura 10a, b, c). Las de sección circular son: a) de forma troncocónica doble; b) fusiformes; c) con "cabezas" hiperbólicas en cada extremidad (Figura 10d, e, f).

Arcos: En seis tumbas aparecieron restos de madera, algunos muy retorcidos, que fueron identificados como arcos; hay evidencia de embarrilado en los extremos $\mathrm{y}$, en un caso, a $10 \mathrm{~cm}$ de cada lado del centro, en una franja de $10 \mathrm{~cm}$ de ancho, probablemente para asegurar la empuñadura. También registramos fragmentos de astiles para flechas; solamente uno de ellos presentaba decoración consistente en dos franjas de pintura blanca alrededor. Fueron encontradas generalmente en tumbas masculinas, aunque se da el caso del hallazgo de fragmentos de astiles en el contexto de una mujer, debidamente caracterizados por el sector de embarrilado que creemos se relaciona con el acoplamiento del cabezal. En otra tumba femenina se registró una punta lítica.

Podrían corresponder estos artefactos a un tipo de instrumento no relacionado con el arco, y que fuera de uso femenino (?). Cabe destacar que de los seis arcos del sitio, cuatro estaban en contexto masculino y dos con niños.

Ganchos de atalaje: Se encontraron dos ganchos para amarrar la carga sobre llamas, hechos en secciones de ramas de chañar, toscamente modelados. Uno en entierro masculino y otro en tumba de mujer.

Agujas: Hay 16 agujas de las cuales dos son de madera y las demás de espinas de cactáceas, ubicadas en tumbas femeninas $(n=6)$, masculinas $(n=2)$ e infantes $(n=2)$. 
RECONSTITUCION FISICA Y CULTURAL DE LA POBLACION TARDIA DEL CEMENTERIO DE QUITOR 6...

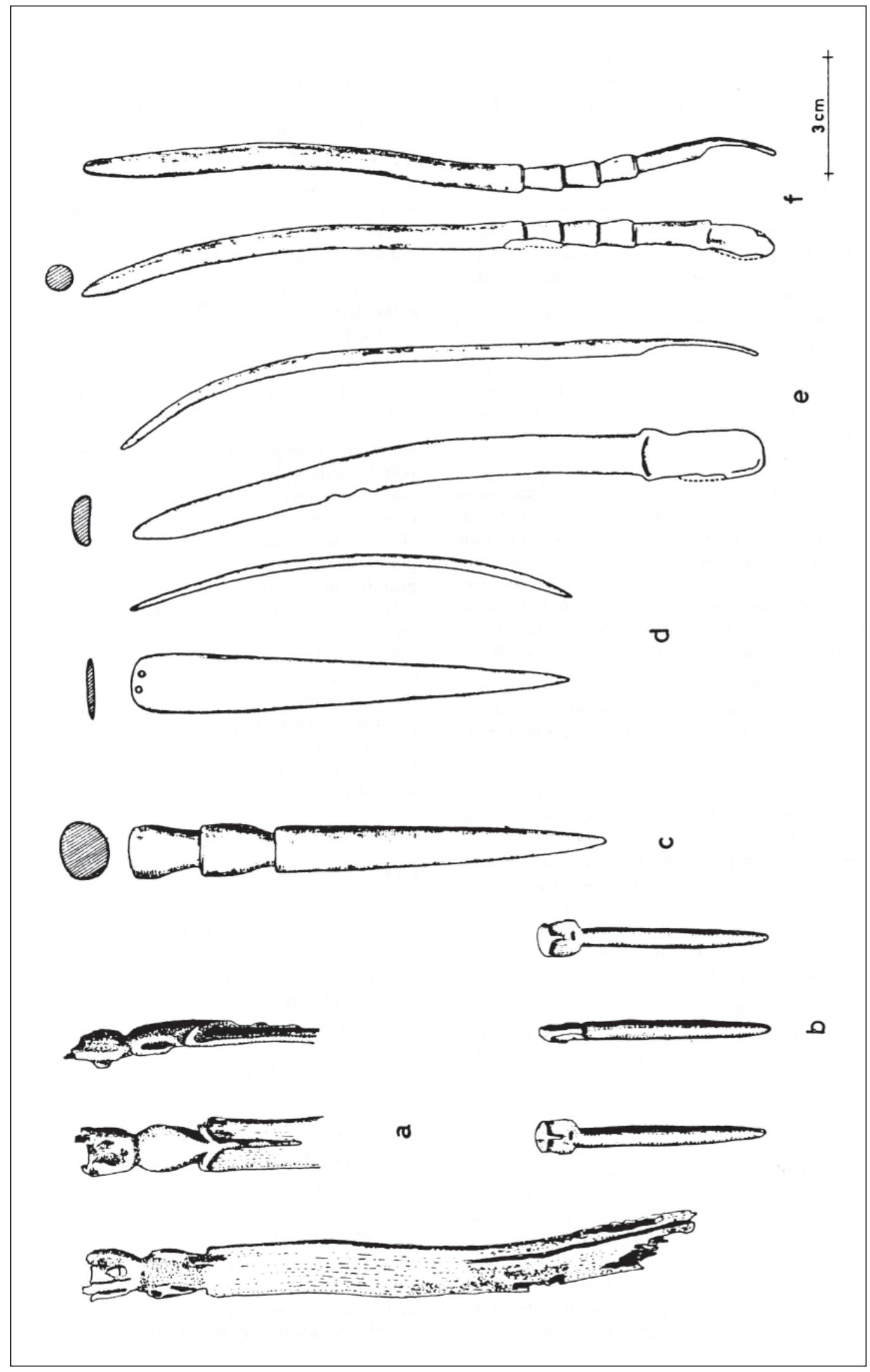



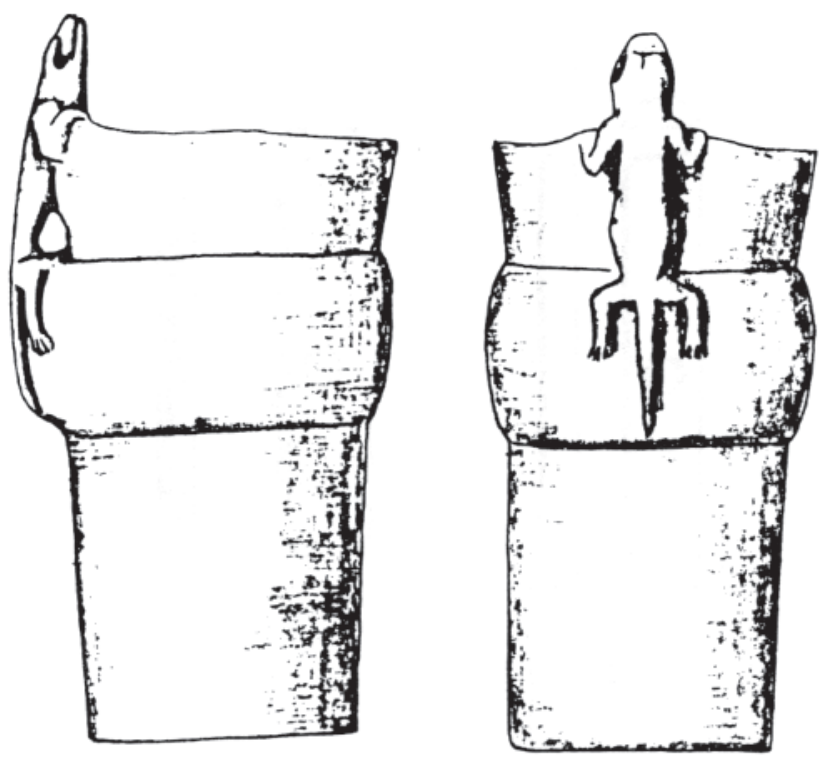

a
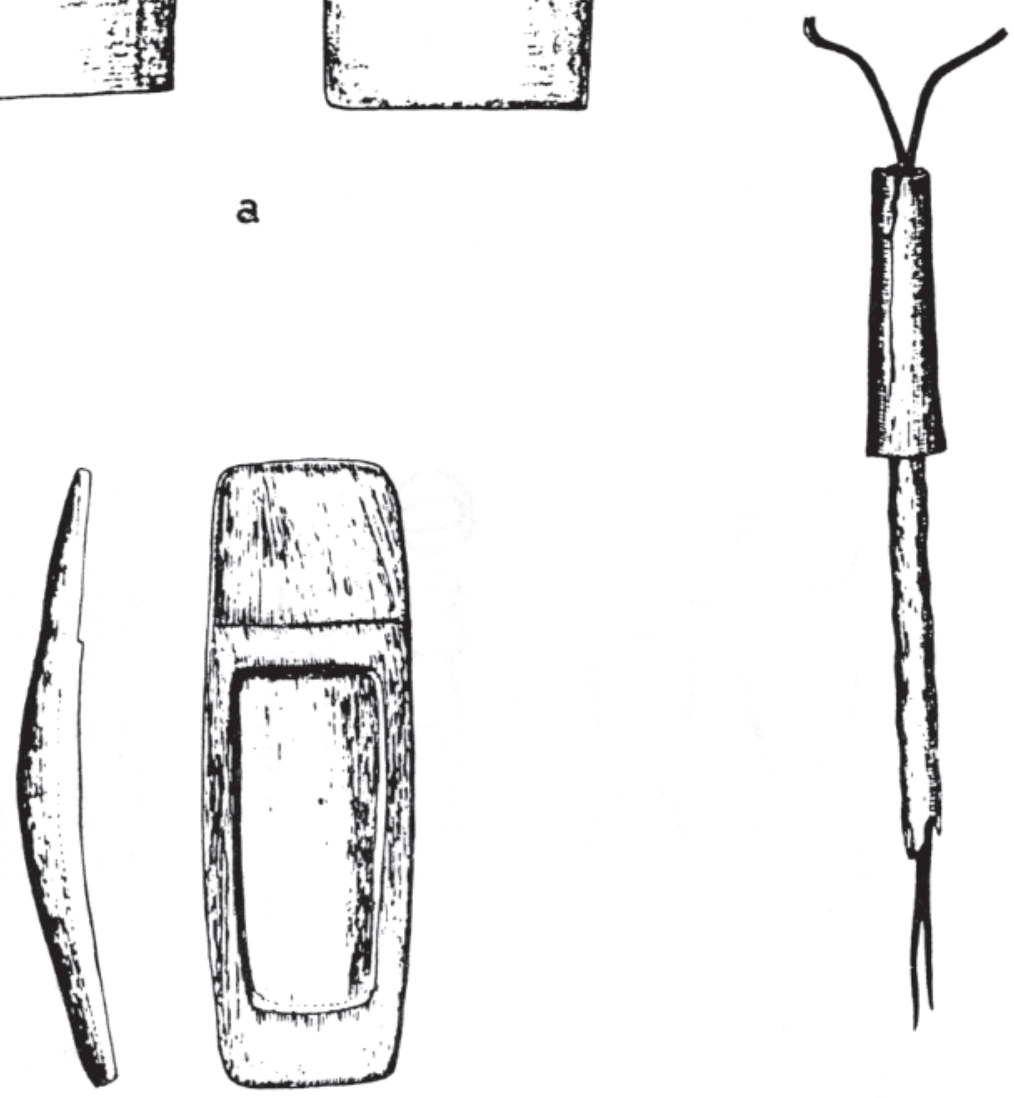

b

C

Figura 9. Objetos de madera encontrados en Quitor 6. 
Peinetas: Fueron cinco las peinetas halladas, tres con mujeres y dos con niños.

Miscelánea: En esta categoría hay un mango que tanto podría ser de espátula como de cuchara. Muestra una decoración con tallado tridimensional y volumétrico, consistente en una figura zoomorfa agazapada sobre el extremo proximal. La cara está apenas insinuada por el tallado en relieve de la nariz; al parecer tuvo grandes orejas. En la parte posterior de la figura, la cola es representada verticalmente como orientada hacia abajo, en el patrón propio de este tiempo preincaico, ya advertido en el kero de madera (L. Núñez, com. pers.). Fue encontrado en tumba femenina (Figura 8a). Otra pieza de miscelánea es un palito de $2.7 \mathrm{~cm}$ de largo por $0.5 \mathrm{~cm}$ de diámetro, con cuatro perforaciones que lo traspasaron de lado a lado y que interpretamos como porciones finales de un collar de cuentas (tipo colgante).

\section{Hueso}

En esta categoría tenemos apenas ocho objetos:

Espátulas: Las dos espátulas fueron encontradas en una tumba masculina y ambas son de hechura muy sencilla. En una de ellas (Figura 8d) se hicieron dos orificios en la extremidad proximal, tal vez con la finalidad de colgarla. El extremo aguzado se encuentra muy pulido, aparentemente por el uso.

Cucharas: Las dos cucharas se encuadran en la Familia II de Espoueys (1972-73), grupo F. Una de ellas es muy sencilla (Figura 11a). La otra tiene pala en forma hiperbólica con un rebaje acompañando el contorno, dejando un borde saliente (Figura 11b); está fracturada y presenta orificios de remiendo a cada lado de la fractura. La primera fue encontrada en contexto masculino y la otra, en uno femenino.

Tubo: Está formado por una porción de hueso largo de animal no identificado, sin decoración. Se aprecian marcas producidas por un instrumento cortante alrededor de los bordes (tumba de mujer).

Cuentas de collar: Se confeccionaron de matrices de huesos largos, recortados y pulidos en forma de paralelepípedos, con una perforación practicada al centro, para enhebrar las cuentas (tumba femenina).

Miscelánea: Un objeto fabricado con la escápula de un animal no identificado, recortada y con los bordes pulidos; está fracturado y su función es desconocida.

Metal

Encontramos 10 anillos, seis de plata y cuatro de cobre, todos trabajados en láminas finas de metal, cortadas en bandas que van de 0.8 a $2.2 \mathrm{~cm}$ de ancho, ajustables al diámetro del dedo. Seis eran de mujeres (tres en plata y tres en cobre) y cuatro de niños (uno en cobre y tres en plata). Hay exclusión del sexo masculino para este tipo de adorno.

Adicionalmente se registraron dos bandas de plata, colocadas ambas sobre la cara de los individuos, en un hombre y en un niño, respectivamente. Se halló también un pequeño disco de plata en un entierro infantil; la falta de perforación invalida su uso como pendiente (función desconocida).

Lítico: Esta industria se representa por tres puntas de proyectil triangulares, bordes levemente convexos, finamente presionados, con aletillas dirigidas hacia atrás y pedúnculo (Figura 11e). Una de ellas estaba en tumba femenina, las demás con hombres.

Un alto porcentaje de contextos (76.6\%) presentó 41 collares de cuentas, confeccionados en oxidados de cobre $(70.73 \%)$ y en toba riolítica (liparita). Encontramos varias cuentas talladas en piedra. Son frecuentes las planiformes, recortadas en forma trapezoidal y confeccionadas preferentemente en cuarzo oscuro. Tres de ellas fueron posteriormente talladas para obtener la forma de una llama; se encuentran en diferentes etapas de talla, pero la más completa presenta el cuerpo recortado, las patas definidas y la cabeza bien terminada (tumba femenina).

Otra forma es la miniatura de un zorro; están representadas las orejas y la boca. Una escotadura circular forma el cuello; cuerpo cónico con cuatro pequeñas patas y cola insinuada (Figura 11d). Se encuentra también una figura de un ave bicéfala, en la cual están bien representadas las alas, el cuerpo y una de las cabezas; la otra está fracturada (Figura 11c). La primera cuenta estaba con un niño, la segunda con una mujer.

\section{Textiles}

Esta categoría se basa en evidencias mal conservadas en el sitio, pero pudimos observar que la técnica más popular fue la de "tejido plano" (Fung 1958-59), 

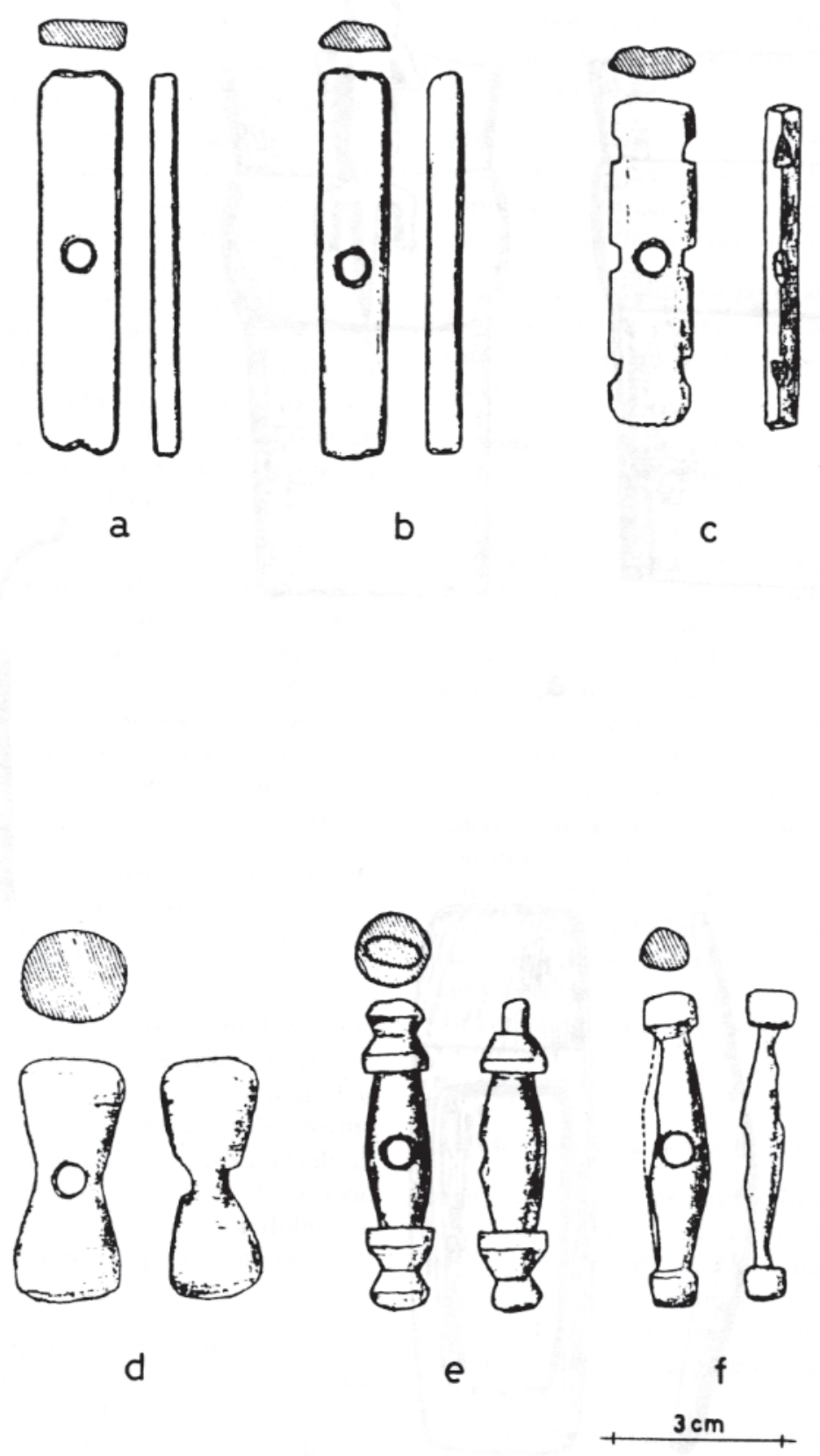

Figura 10. Torteras encontradas en Quitor 6. 


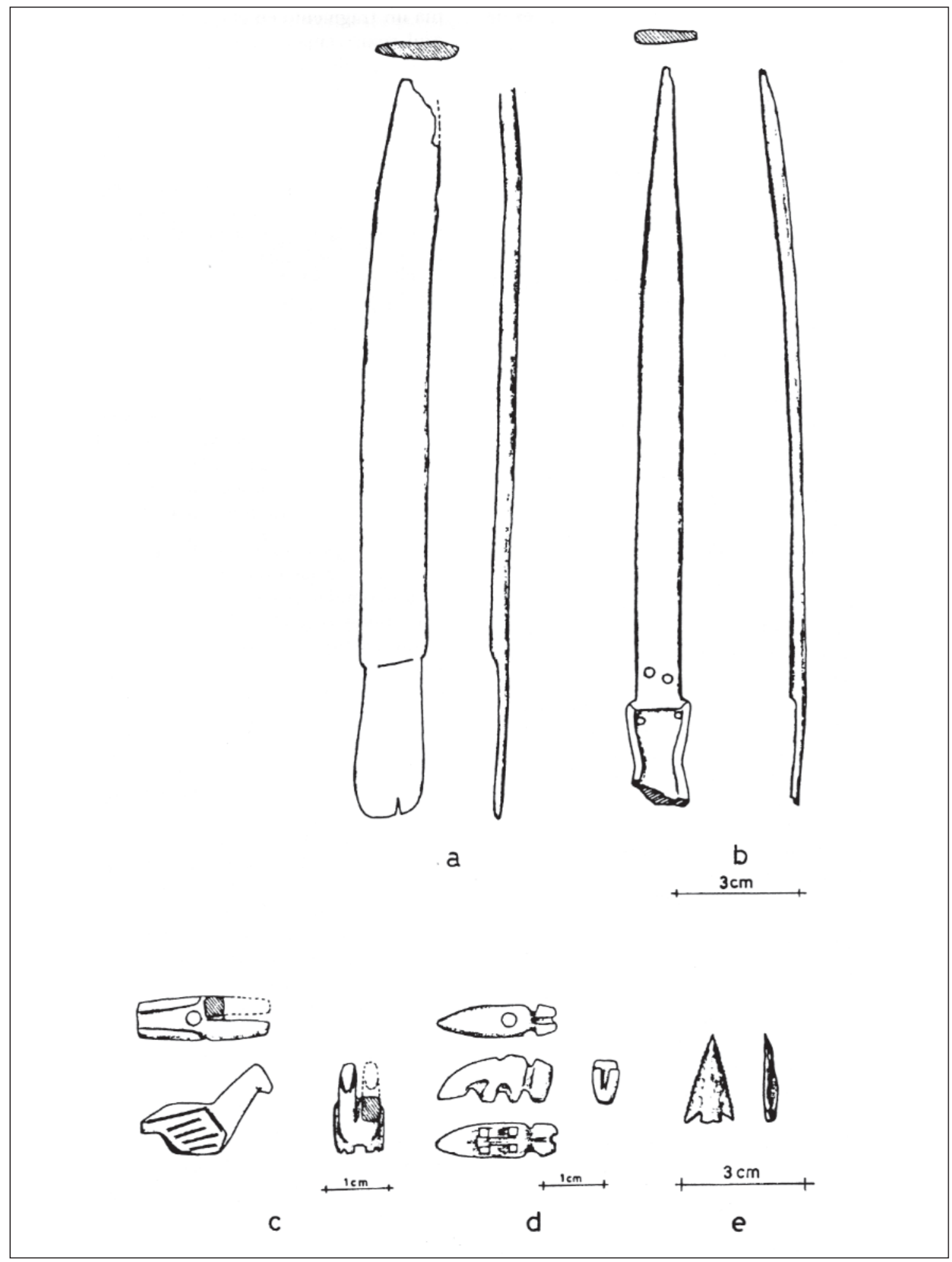

Figura 11. Artefactos encontrados en Quitor 6. 
en faz de urdimbre. Predomina el hilo de lana de dos cabos, hilado en $\mathrm{Z}$ y torcido en $\mathrm{S}$. Los colores son naturales, que van del café claro al negro; se exceptúa un fragmento en el que se usaron hilos de colores azul, rojo, crema y negro como urdimbre, dispuestos en franjas de diferentes anchos. En ese mismo fragmento se usó otra técnica de decoración, empleando la textura como elemento decorativo, en lugar del color; ahí se presentan franjas donde el tejido plano se cambia por otro patrón, en el cual los hilos de la trama se trasponen por cerca de 15 hilos de urdimbre, retomando a seguir el sistema plano. El fragmento es pequeño y está muy plegado, pero se pueden reconocer dos franjas con esta técnica.

En cuanto a la función de las piezas encontradas, solamente pudimos reconocer un posible fragmento de camisa, cuatro bolsas y tres frazadas. Es frecuente el uso de remiendo en los tejidos analizados.

Cordelería: Se empleó la lana para confeccionar cordeles, la mayor parte en sus colores naturales; solamente un cordel fue teñido de rojo. También la fibra vegetal fue usada. La torsión es preferentemente en S. Predominan los cordeles de grosor medio (0.5-1.0 cm de diámetro), de tres cabos.

Gorros o tocados cefálicos: En el sector del sitio de Quitor 6 que trabajamos no se pudo recuperar ningún tocado completo, siendo su única evidencia el soporte de fibras vegetales. Estos eran realizados básicamente en tres técnicas: a) simple plaited (Adovasio 1977), donde ambos elementos del tejido son activos y ambos pasan alternativamente por sobre y por debajo del otro; b) espiral de cuerda, enrollándola sobre sí misma para formar un cilindro de diámetro igual a la circunferencia de la cabeza, c) anillo de cuerda gruesa, cuyas extremidades se atan con un cuero muy delgado.

Estos elementos aparecieron en 13 tumbas (30, 95\%) de las cuales nueve eran de hombres, tres de niños y una de mujer. En este último caso, el estado de conservación in situ era muy malo, desintegrándose durante la excavación, lo que imposibilita la confirmación de que realmente se trataba de un soporte de tocado. Este punto es importante porque se podría estar configurando aquí una manifestación de dimorfismo cultural, según el cual los hombres preferentemente usaban este tipo de adorno cefálico.
Flora

En 23 tumbas se evidenció la colocación de ofrendas de vainas de algarrobo (Prosopis chilensis); el maíz (Zea mays) apareció en 16 ocasiones y el chañar (Geoffrea decorticans) en sólo dos.

Fauna

En dos enterratorios aparecieron esqueletos de cánidos asociados a un hombre y una mujer, ubicados en tumbas vecinas. Los camélidos eran muy frecuentes, testimoniados por la presencia de huesos de las patas.

Las evidencias malacológicas se advierten en cinco tumbas y todas son especies marinas: dos Protothaca thaca, tres Oliva peruviana (usadas como cuentas de collar) y un fisurélido (lapa).

\section{Material osteológico}

Material y métodos

La muestra se compone de 47 individuos. De éstos, 46 fueron encontrados en condición de esqueletos y uno, de fardo funerario; este último fue conservado en esa forma y, por lo mismo, no lo pudimos estudiar. En general, las condiciones de conservación fueron buenas y la recuperación de los esqueletos prácticamente total.

Las medidas e índices craneométricos fueron obtenidos según la técnica de Vallois (1965), conforme a los acuerdos internacionales para la estandarización antropométrica. Para el cálculo de la talla de los individuos se usaron las tablas de Trotter y Gleser (1958) elaborada para mexicanos.

Para la estimación del sexo consideramos la morfología pélvica y craneana (Bass 1971; Ubelaker 1978). En la determinación de la edad de los adultos, empleamos los signos de maduración de la sínfisis pubiana (McKern y Stewart 1957; Gilbert y McKern 1973; Meindl et al. 1985), la sinostosis de las suturas craneanas (Meindl et al. 1985) y los cambios en la superficie auricular del ílium (Lovejoy et al. 1985). Para los subadultos, utilizamos la fusión de la sincodrosis esfenooccipital; la osificación y fusión de la epífisis; la calcificación y el estado de erupción dentaria (Ubelaker 1978). 
Finalmente, nos basamos en el trabajo de Droessler (1981) para el análisis de las deformaciones craneanas, y en el de Castro y Quevedo (1983) para el de rasgos no métricos.

\section{Paleodemografía}

Esta población se compone de 33 adultos y 14 subadultos; entre los primeros se estableció la presencia de 22 mujeres y 11 hombres.

De acuerdo a los criterios empleados, se determinaron nueve grupos etarios para esta población, con intervalos de cinco años:

Lactantes (L)

Primera Infancia (1I)

Segunda Infancia (2I)

Subadulto (SA)

Adulto Joven (AJ)

Adulto (A)

Adulto Maduro (AM)

Adulto Maduro Avanzado (AMA)

Más de 40 años (+40)

Observando la tabla de vida (Cuadro 2) vemos que la representación de muertes de lactantes es la más alta para los niños (22.2\%). Entre los adultos el mayor porcentaje se da en el grupo Adulto Maduro Avanzado, también con $22.2 \%$, seguido por el de Adulto (17.8\%). ${ }^{3}$ Lo anterior estaría indicando que los primeros años de vida son críticos en esta población, alcanzando el mayor porcentaje de muertes entre los dos y cuatro años de edad, lo que coincide con el período del destete. Pero una vez superada esta fase el individuo tiene buenas posibilidades de llegar a una edad avanzada.

Pudimos determinar el sexo con seguridad del total de individuos adultos y nos encontramos con el hecho de que la población femenina duplica a la masculina. Destacamos que los individuos de ambos sexos están distribuidos proporcionalmente en todas las fajas etarias; esto invalida una explicación de alta mortalidad femenina debido a riesgos en el proceso reproductivo, relacionados con embarazo y parto. Este desequilibrio se manifiesta contrario al fenómeno biológico según el cual hay una mayor natalidad y también una mayor mortalidad entre los individuos masculinos de una población de mamíferos (Clarke 1965). Se supone también, que ésta es una población con patrón de vida sedendatario, lo que hace que los riesgos de muerte para los varones del grupo sean mínimos, debido a la menor posibilidad de accidentes de trabajo lejos del asentamiento (p.e., la caza), y el consecuente enterramiento fuera del cementerio local.

A pesar de lo reducido de la muestra, y la reserva que merece el estudio paleodemográfico en tales condiciones, se preparó una curva de sobrevivencia para esta población, la que se muestra en la Figura 12.

\begin{tabular}{|c|c|c|c|c|c|c|c|}
\hline $\mathbf{x}$ & $\mathbf{D c}$ & $\mathbf{d x}$ & $\mathbf{l x}$ & $\mathbf{q x}$ & $\mathbf{L x}$ & $\mathbf{T x}$ & $\mathbf{c}^{\mathbf{0}} \mathbf{x}$ \\
\hline $0-4$ & 10 & 22.22 & 100.00 & 0.222 & 444.450 & 2.661 .450 & 26.61 \\
$5-9$ & 1 & 2.22 & 77.78 & 0.028 & 383.350 & 2.217 .000 & 28.50 \\
$10-14$ & 1 & 2.22 & 75.56 & 0.029 & 372.250 & 1.833 .650 & 24.27 \\
$15-19$ & 1 & 2.22 & 73.34 & 0.030 & 361.150 & 1.461 .400 & 19.93 \\
$20-24$ & 2 & 4.44 & 71.72 & 0.062 & 344.500 & 1.100 .250 & 15.47 \\
$25-29$ & 8 & 17.78 & 66.68 & 0.267 & 288.950 & 755.750 & 11.33 \\
$30-34$ & 6 & 13.34 & 48.90 & 0.273 & 211.150 & 466.800 & 9.55 \\
$35-39$ & 10 & 22.22 & 35.56 & 0.625 & 122.250 & 255.650 & 7.19 \\
$40-+$ & 6 & 13.34 & 13.34 & 1.000 & 133.400 & 133.400 & 10.00 \\
\hline & 45 & 100.00 & - & - & 2.661 .450 & - & - \\
\hline
\end{tabular}

Cuadro 2. Tabla de vida.

\footnotetext{
3 No están considerados en esta tabla una mujer adulta a la que no fue posible determinar la edad, ni el niño en el fardo funerario.
} 


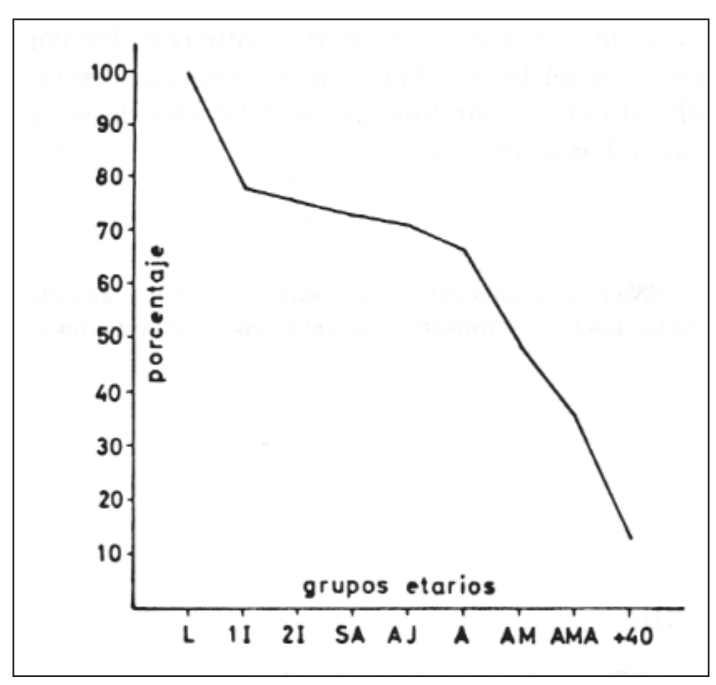

Figura 12. Curva de sobrevivencia

\section{Deformación craneana}

Fueron analizados 34 cráneos para tipificar las deformaciones craneanas intencionales, considerando en el análisis: a) los huesos afectados por la práctica deformatoria; b) el grado de deformación verificado. Registramos dos tipos simples de deformación y uno combinado, que son, respectivamente: frontal, lambdoidal y frontoccipital.

Hay una alta proporción de cráneos con deformación $(\mathrm{n}=20)$, lo que significa que el $58.8 \%$ de los individuos examinados está deformado. Predomina el tipo frontoccipital (40\%), seguido por el frontal (30\%), mientras que el lambdoidal alcanza el $25 \%$. No advertimos diferencias sexuales en la práctica deformatoria, ya que ambos sexos están representados en todos los tipos; solamente se observa un leve predominio de mujeres deformadas. Tampoco detectamos sectorización en el cementerio, ni diferenciación de contextos culturales en relación a los tipos de deformación.

\section{Rasgos no métricos}

Se verifica una alta incidencia de caracteres no métricos en esta población. Fue notorio que los agujeros y escotaduras supraorbitarios fueron los rasgos más predominantes, ya que el $100 \%$ de los individuos los presenta. Son recurrentes también los surcos del frontal y los agujeros espurios (58.6\% cada uno); las ramas emisarias de la arteria meníngea media y la dehiscencia de la placa timpánica (55.2\%); el agujero innominado $(51.7 \%)$. El conducto lateral alcanzó apenas $3.44 \%$ y, como era de esperarse en una población no costera, el torus auditivo estuvo completamente ausente.

\section{Caracteres métricos}

A base de seis índices craneométricos (craneano horizontal, vértice longitudinal, vértico transversal, facial total, facial superior, nasal y orbitario), estimamos que ésta es una población con fuerte predominancia de cráneos redondeados y bajos; las caras tienden a ser medianas en el ancho; las órbitas estrechas y las narices medianas (Cuadro 3). La estatura promedio es de $156 \mathrm{~cm}$ siendo el promedio masculino de $160 \mathrm{~cm}$ y el femenino de $154 \mathrm{~cm}$ (Cuadro 4).

\section{Paleopatología general y traumatismo}

Aparato masticador y sistema dentario. Fueron examinadas las dentaduras de 28 individuos adultos y de siete subadultos, en un total de 560 piezas permanentes y 130 decíduas. Hay una importante patología dental en esta población, traducidas en una alta incidencia de caries, de enfermedades peridontales y de lesiones periapicales. Llama la atención la fuerte abrasión que se registra desde edades muy tempranas de los individuos. La dieta generalmente atribuida a las sociedades agrícolas, blanda y rica en carbohidratos, explicaría la abundancia de caries pero no la abrasión verificada.

Contabilizamos un total de 264 piezas cariadas en los 35 individuos, los que representan el $74.4 \%$ del total de la población, con un promedio de 7.5 caries por persona. El resto de la población se compone de lactantes, de adultos sin dentadura, o de cuerpos sin el cráneo. O sea, se puede considerar que la totalidad de la muestra se encuentra afectada por esta patología. Las mujeres presentan más del doble de caries que los hombres, lo que atribuimos a los desequilibrios resultantes de la gestación y de la lactancia y, tal vez, por la masticación del maíz en la preparación de chicha.

Se observa la abrasión dentaria de los tipos plano y excavado (Molnar 1972); la abrasión prematura y acentuada es propia de poblaciones con dietas duras, como es el caso de las costeras y no de una población agrícola como la que nos ocupa. Creemos que las partículas líticas incluidas en la alimentación derivada de la molienda de granos 
RECONSTITUCION FISICA Y CULTURAL DE LA POBLACION TARDIA DEL CEMENTERIO DE QUITOR 6...

\begin{tabular}{|c|c|c|c|c|c|c|c|c|c|c|c|c|c|c|c|c|c|}
\hline Івұ!q.Јо әә!риІ & 0 & $\stackrel{m}{m}$ & $\stackrel{\circ}{\infty}$ & $\begin{array}{l}\text { م̊ } \\
\text { ล̊ }\end{array}$ & $\begin{array}{l}\text { ホ } \\
\dot{J}\end{array}$ & $\frac{\dot{d}}{+\infty}$ & 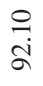 & $\begin{array}{l}\infty \\
\infty \\
\infty \\
\infty\end{array}$ & $\underset{m}{\infty}$ & $\forall$ & & $\begin{array}{l}\text { जे } \\
\text { ¿े }\end{array}$ & $\begin{array}{l}\stackrel{\infty}{\infty} \\
\frac{\infty}{\infty}\end{array}$ & $\begin{array}{l}\stackrel{n}{7} \\
\text { in }\end{array}$ & $\begin{array}{l}\stackrel{0}{a} \\
\text { ă }\end{array}$ & 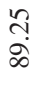 & in \\
\hline [вSEu әэ!рuI & 6 & $\frac{\delta}{n}$ & \begin{tabular}{l}
\multirow{\sigma}{\sigma}{} \\
$\dot{\infty}$
\end{tabular} & $\begin{array}{l}8 \\
\text { ○े } \\
\stackrel{+}{0}\end{array}$ & $\frac{5}{\frac{7}{f}}$ & $\begin{array}{l}8 \\
\text { í }\end{array}$ & $\frac{\text { ô }}{n}$ & $\begin{array}{l}\hat{b} \\
\dot{\infty} \\
\dot{+}\end{array}$ & $\stackrel{+}{+\infty}$ & $\forall$ & & $\begin{array}{l}8 \\
\text { in }\end{array}$ & $\begin{array}{l}\hat{\sigma} \\
\text { oे }\end{array}$ & $=$ & $\stackrel{m}{\hat{n}}$ & mे & $\begin{array}{l}\text { : } \\
i\end{array}$ \\
\hline 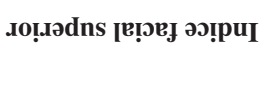 & 6 & 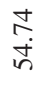 & $\begin{array}{l}0 \\
\text { in } \\
\text { ñ }\end{array}$ & $\begin{array}{l}F \\
\text { in }\end{array}$ & $\begin{array}{l}\text { No } \\
\text { ڤn }\end{array}$ & $\begin{array}{l}8 \\
\stackrel{8}{0} \\
\text { in }\end{array}$ & $\begin{array}{l}2 \\
\text { in } \\
\text { in }\end{array}$ & $\begin{array}{l}m \\
\stackrel{D}{n}\end{array}$ & $\stackrel{\overbrace{}}{i}$ & $\forall$ & & 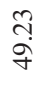 & $\frac{\hat{\sigma}}{\dot{\gamma}}$ & $\begin{array}{l}\text { 于े } \\
\dot{f}\end{array}$ & 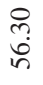 & $\frac{\partial}{n}$ & 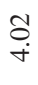 \\
\hline 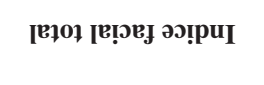 & in & 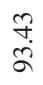 & $\begin{array}{l}n \\
\tilde{n} \\
\tilde{n}\end{array}$ & $\bar{a}$ & $\frac{2}{a}$ & l & $\frac{n}{a}$ & $\begin{array}{l}\text { 文 } \\
\text { ๙் }\end{array}$ & ふূे & $m$ & & $\begin{array}{l}8 \\
\stackrel{8}{0} \\
\infty\end{array}$ & 1 & $\begin{array}{l}\hat{a} \\
\grave{\alpha}\end{array}$ & $\frac{\infty}{+}$ & $\begin{array}{l}\text { mे } \\
\text { ๙े }\end{array}$ & $\begin{array}{l}\infty \\
\infty \\
i\end{array}$ \\
\hline 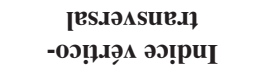 & $n$ & $\frac{0}{\frac{1}{\infty}}$ & 1 & $\begin{array}{l}\stackrel{q}{+} \\
\stackrel{+}{\infty}\end{array}$ & సֶ. & 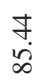 & $\begin{array}{c}\infty \\
\infty \\
\infty \\
\infty \\
\infty\end{array}$ & సֶ. & $\stackrel{\infty}{\sim}$ & $\forall$ & & $\begin{array}{l}\text { I } \\
\text { त }\end{array}$ & $\begin{array}{l}\bar{\infty} \\
\ddot{\infty}\end{array}$ & $\begin{array}{l}\hat{0} \\
\dot{+}\end{array}$ & ले. & $\begin{array}{l}8 \\
\dot{0} \\
\dot{\infty}\end{array}$ & నू \\
\hline 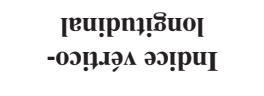 & $n$ & $\begin{array}{l}m \\
m \\
\stackrel{\infty}{ \pm}\end{array}$ & 1 & $\begin{array}{l}\hat{b} \\
\dot{j} \\
\dot{J}\end{array}$ & $\begin{array}{l}8 \\
0 \\
\dot{0} \\
\pm\end{array}$ & $\begin{array}{l}8 \\
\stackrel{8}{ \pm}\end{array}$ & 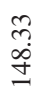 & $\begin{array}{l}0 \\
\stackrel{0}{0} \\
\dot{0}\end{array}$ & $\stackrel{+}{G}$ & $\checkmark$ & & $\begin{array}{l}\stackrel{8}{ } \\
\stackrel{+}{+} \\
\text { I }\end{array}$ & $\begin{array}{l}\stackrel{m}{\Xi} \\
\dot{J}\end{array}$ & $\begin{array}{l}\hat{\sigma} \\
\hat{\sigma} \\
\underline{-}\end{array}$ & $\begin{array}{l}m \\
\text { ’’ } \\
\dot{q}\end{array}$ & 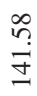 & $\underset{\substack{\infty \\
i}}{ }$ \\
\hline 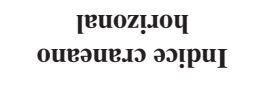 & 6 & $\underset{0}{\stackrel{\infty}{\infty}}$ & $\begin{array}{l}0 \\
\text { గి } \\
\infty\end{array}$ & $\begin{array}{l}\vec{b} \\
\dot{\infty}\end{array}$ & $\begin{array}{l}\infty \\
\infty \\
\infty \\
0\end{array}$ & $\frac{\hat{n}}{\infty}$ & 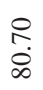 & $\stackrel{\text { I }}{\stackrel{\infty}{*}}$ & $\stackrel{\infty}{\dot{m}}$ & $\nabla$ & & $\begin{array}{l} \pm \\
\dot{a}\end{array}$ & $\stackrel{n}{\mathfrak{n}}$ & $\begin{array}{l}\tilde{n} \\
\ddot{\infty}\end{array}$ & $\frac{\infty}{\stackrel{\infty}{+}}$ & $\begin{array}{l}\text { ஜర } \\
\infty \\
\infty\end{array}$ & $\stackrel{\circ}{\circ}$ \\
\hline [в]!q.10 очэи V & 6 & Y & $\hat{n}$ & 우 & $\infty$ & $\stackrel{F}{+}$ & $\infty$ & q & $\stackrel{\stackrel{N}{\sim}}{\stackrel{d}{*}}$ & $\nabla$ & & $\hat{n}$ & Ұ & 우 & $\infty$ & ले & $\underset{\text { Do }}{\infty}$ \\
\hline [в]!q.IO в.In†IV & 6 & $\tilde{m}$ & $m$ & $\hat{n}$ & లి & $\tilde{m}$ & $\ddot{n}$ & $\tilde{m}$ & m? & $\nabla$ & & $\ddot{m}$ & ల & $m$ & $\tilde{m}$ & $m$ & 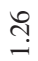 \\
\hline z!..8и оцगи V & 0 & $\approx$ & $\ddot{\sim}$ & 가 & $\approx$ & $\hat{\imath}$ & $\approx$ & $\stackrel{\sim}{\sim}$ & $\stackrel{\stackrel{\circ}{+}}{i}$ & $\nabla$ & & $\stackrel{\sim}{N}$ & $\ddot{\sim}$ & $\ddot{\lambda}$ & $\stackrel{+}{\sim}$ & $\ddot{\lambda}$ & $\stackrel{\infty}{n}$ \\
\hline Z!.IBu b.InIIV & 6 & $\stackrel{q}{q}$ & ซ & in & $n$ & 요 & gे & $\stackrel{\circ}{n}$ & $\hat{\sigma}$ & 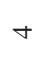 & & $\stackrel{\infty}{+}$ & $g$ & ケ & 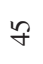 & g & $\stackrel{n}{0}$ \\
\hline 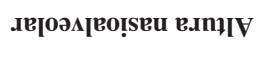 & 6 & 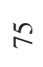 & $\hat{b}$ & 咅 & $\stackrel{2}{2}$ & $\stackrel{\mathscr{\theta}}{\theta}$ & 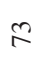 & $\stackrel{N}{ }$ & $\frac{\circ}{\stackrel{r}{m}}$ & 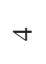 & & ţ & हn & $\hat{\sigma}$ & $\hat{6}$ & ț & $\stackrel{\gtrless}{\stackrel{r}{r}}$ \\
\hline 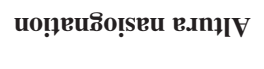 & 6 & $\stackrel{\infty}{\simeq}$ & $\stackrel{0}{=}$ & $\cong$ & 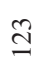 & I & త & 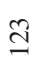 & $\underset{+}{\stackrel{\forall}{+}}$ & $m$ & & $\Xi$ & 1 & $\stackrel{\infty}{=}$ & $\stackrel{0}{=}$ & $\cong$ & $\underset{\dot{r}}{\stackrel{8}{ }}$ \\
\hline 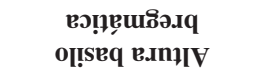 & $n$ & $\ddot{n}$ & 1 & $\stackrel{\infty}{\sim}$ & $\stackrel{\sim}{-}$ & $\stackrel{\sim}{\sim}$ & 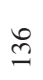 & $\stackrel{m}{=}$ & $\frac{m}{m}$ & $\checkmark$ & & $\stackrel{\sim}{I}$ & $\stackrel{\overbrace{}}{\cong}$ & $\stackrel{さ}{\beth}$ & $\widehat{\mathrm{I}}$ & $\stackrel{\circ}{\sim}$ & $\begin{array}{l}\widehat{\infty} \\
i\end{array}$ \\
\hline 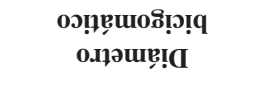 & 6 & $\hat{n}$ & $\stackrel{\overparen{J}}{\stackrel{\Xi}{\Xi}}$ & 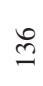 & 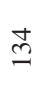 & 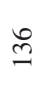 & $\stackrel{\overbrace{}}{\varrho}$ & $\stackrel{m}{-}$ & 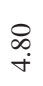 & $\checkmark$ & & $\stackrel{\text { }}{-}$ & 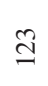 & 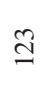 & $\stackrel{\varrho}{=}$ & 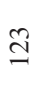 & $\hat{n}$ \\
\hline ou!xpц очगuV & 6 & 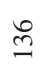 & 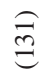 & $\stackrel{\infty}{\sim}$ & $\ddot{n}$ & $\underset{J}{ \pm}$ & $\stackrel{\infty}{\sim}$ & $\hat{n}$ & $\stackrel{n}{n}$ & 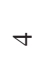 & & 导 & 导 & mे & $\stackrel{\sim}{2}$ & $\stackrel{\infty}{\sim}$ & 导 \\
\hline 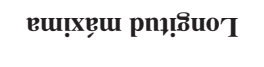 & 6 & $\stackrel{ \pm}{I}$ & $\underline{\sigma}$ & $\sqrt{6}$ & $\stackrel{\cong}{I}$ & $\underline{6}$ & $\Xi$ & જิ & 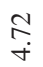 & 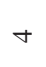 & & $\stackrel{\infty}{\curvearrowleft}$ & 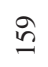 & 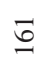 & ్ㅡ & $\stackrel{8}{0}$ & $\stackrel{\infty}{-}$ \\
\hline 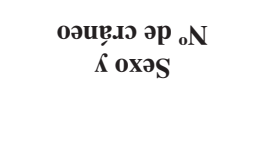 & 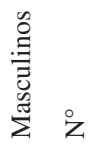 & 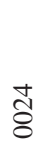 & है & $\frac{0}{\mathbb{1}}$ & ๙ิ & \begin{tabular}{l}
0 \\
\hdashline \\
\hdashline
\end{tabular} & $\approx$ & $\ddot{x}$ & 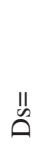 & 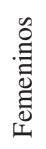 & Z & $\begin{array}{l}\stackrel{8}{\infty} \\
\stackrel{8}{8}\end{array}$ & ญิ & $\begin{array}{c}\infty \\
\infty \\
ల\end{array}$ & ڤे & $\stackrel{I I}{\approx}$ & $\stackrel{\| n}{\mathscr{\omega}}$ \\
\hline
\end{tabular}




\begin{tabular}{|c|c|c|c|c|c|c|c|c|c|c|c|c|c|c|c|}
\hline \multicolumn{16}{|c|}{ Hombres } \\
\hline \multirow{2}{*}{$N^{\circ}$ tumba } & \multirow{2}{*}{$\begin{array}{c}\mathrm{N}^{0} \\
\text { esqueleto }\end{array}$} & \multirow{2}{*}{ Edad } & \multicolumn{2}{|c|}{ Húmero } & \multicolumn{2}{|c|}{ Radio } & \multicolumn{2}{|c|}{ Cúbito } & \multicolumn{2}{|c|}{ Fémur } & \multicolumn{2}{|c|}{ Tibia } & \multicolumn{2}{|c|}{ Peroné } & \multirow{2}{*}{$\begin{array}{l}\text { Estatura } \\
\text { calculada }\end{array}$} \\
\hline & & & D & I & D & I & D & I & D & I & D & I & D & I & \\
\hline 02 & 0024 & AMA & 314 & 311 & 242 & 244 & 266 & 269 & 440 & 441 & 377 & 380 & & 367 & $\begin{array}{c}\mathrm{N}=11 \\
1.67\end{array}$ \\
\hline 06 & 0057 & AMA & 276 & 276 & 227 & 229 & 245 & 247 & & & 342 & & 32 & (325) & 1.57 \\
\hline 11 & 0124 & A & 322 & 311 & & 241 & 263 & 255 & 430 & 431 & 370 & 369 & 36 & 364 & 1.65 \\
\hline 19 & 0270 & $\mathrm{AM}$ & 312 & 308 & 230 & 228 & 247 & 250 & 409 & (413) & 350 & & 23 & 237 & 1.59 \\
\hline 22 & 0303 & $\mathrm{~A}$ & & 293 & 234 & 233 & 251 & 254 & 419 & 416 & 354 & 351 & 33 & 337 & 1.60 \\
\hline 31 & 0352 & $\mathrm{AM}$ & 326 & 318 & 248 & 252 & 263 & 269 & 445 & 446 & 378 & (377) & 36 & 363 & 1.67 \\
\hline 32 & 0366 & AMA & 269 & 270 & (208) & 211 & 231 & 232 & 378 & 378 & 325 & 321 & 31 & 308 & 1.52 \\
\hline 35 & 0403 & AMA & 319 & 312 & 240 & 240 & 267 & 265 & 425 & 433 & 377 & 372 & & & 1.64 \\
\hline 36 & 0411 & +40 & 309 & 302 & 232 & 221 & 249 & 243 & & & & & 32 & 323 & 1.56 \\
\hline 37 & 0425 & A & 307 & 301 & 235 & 240 & 266 & 260 & 426 & 425 & 367 & 364 & 35 & 356 & 1.63 \\
\hline 51 & 0655 & AMA & 275 & 271 & 212 & 211 & 232 & 232 & 381 & & 323 & 320 & 31 & 314 & 1.53 \\
\hline & & & & & & & & & & & & & & & $\begin{array}{c}\bar{X} 1.60 \\
D s=5.35\end{array}$ \\
\hline \multicolumn{16}{|c|}{ Mujeres } \\
\hline 04 & 0040 & +40 & 284 & 275 & 213 & 216 & 233 & 236 & & & & & 319 & & $\begin{array}{c}\mathrm{N}=22 \\
1.55\end{array}$ \\
\hline 07 & 0071 & AMA & 289 & & 220 & 222 & 238 & 240 & 407 & 408 & 345 & 349 & 340 & 337 & 1.60 \\
\hline 08 & 0080 & AMA & 284 & 280 & 223 & 231 & 240 & 241 & 381 & 384 & 232 & 232 & 317 & 317 & 1.55 \\
\hline 09 & 0088 & AMA & & 291 & 222 & & 208 & 210 & 405 & & (328) & 327 & 311 & 310 & 1.55 \\
\hline 10 & 0104 & $\mathrm{AM}$ & 266 & 264 & 207 & 212 & 237 & 234 & 377 & 379 & 320 & 319 & 312 & 310 & 1.52 \\
\hline 03 & 0108 & +40 & & 282 & 213 & 214 & 233 & & 401 & 394 & 324 & 327 & 307 & 306 & 1.54 \\
\hline 12 & 0135 & $\mathrm{AM}$ & 285 & 276 & 212 & 217 & 233 & 236 & 396 & 396 & 341 & 340 & 325 & 325 & 1.56 \\
\hline 21 & 0293 & +40 & 266 & 264 & 207 & 208 & & 230 & 369 & 375 & 311 & 311 & 305 & 306 & 1.51 \\
\hline 30 & 0339 & A & 268 & 268 & 209 & 208 & 229 & 232 & 379 & 385 & 331 & 331 & 318 & 318 & 1.54 \\
\hline 33 & 0382 & A & 272 & (270) & 199 & 200 & 217 & 219 & & & 315 & 315 & 301 & 302 & 1.54 \\
\hline 34 & 0393 & A & & & 210 & 209 & 229 & 229 & 373 & 372 & 320 & 320 & 313 & 315 & 1.51 \\
\hline 39 & 0432 & +40 & 300 & 291 & 217 & 223 & 247 & 245 & 404 & 409 & 332 & 332 & & & 1.58 \\
\hline 40 & 0447 & A & 287 & 289 & 223 & 217 & 244 & 239 & 388 & 391 & 330 & 330 & 319 & 319 & 1.55 \\
\hline 42 & 0532 & AMA & 284 & 284 & 215 & 214 & 241 & 234 & 390 & 392 & 336 & 337 & 323 & 325 & 1.56 \\
\hline 44 & 0557 & +40 & 300 & 300 & 221 & 215 & 240 & 239 & 403 & 404 & 345 & 347 & 340 & 342 & 1.59 \\
\hline 46 & 0595 & A & 297 & 295 & 215 & 215 & 235 & 237 & 401 & 403 & 333 & 334 & 328 & 326 & 1.59 \\
\hline 47 & 0613 & $\mathrm{AJ}$ & 288 & & 213 & & 232 & & 390 & & 340 & & 331 & & 1.56 \\
\hline 48 & 0623 & $\mathrm{AM}$ & 263 & 258 & 197 & 200 & 221 & 216 & 370 & 369 & 311 & 309 & 304 & 304 & 1.50 \\
\hline 52 & 0667 & AMA & 279 & & 209 & 212 & 233 & 237 & & & 332 & & 229 & 230 & 1.53 \\
\hline 54 & 0685 & AMA & 267 & 265 & 198 & 205 & 229 & 229 & 385 & 388 & 326 & 325 & 316 & 319 & 1.54 \\
\hline 55 & 0694 & AJ & 256 & 249 & 193 & 197 & 213 & 215 & 358 & & 289 & & 278 & 278 & 1.46 \\
\hline 38 & 0943 & $?$ & & & & & & & & & 334 & & 324 & & 1.58 \\
\hline & & & & & & & & & & & & & & & $\begin{array}{l}\bar{X}=1.55 \\
D s=3.30\end{array}$ \\
\hline
\end{tabular}

Cuadro 4. Medidas de los huesos largos y estatura calculada, población adulta. 
en morteros de piedra pudo contribuir al desgaste; otra posibilidad podría ser el efecto de los hábitos masticatorios individuales, determinados por patologías agudas, como pulpites y peridontitis. Examinamos 30 individuos, encontrando un predominio de la forma de abrasión plana, con el $63.3 \%$ de las ocurrencias, con dirección horizontal en un $63.3 \%$ de los casos.

La perforación de la cámara pulpar causada por las caries o por la abrasión intensa ocasiona la necrosis pulpar con la formación de lesiones periapicales manifestada en abcesos y quistes que provocan la excavación de los alveolos y, en muchos casos, la avulsión de las piezas dentarias afectadas. Encontramos 25 individuos con lesiones periapicales, lo que significa el $53.2 \%$ del total de la población, con un promedio de 3.6 lesiones por persona. Un $66.7 \%$ de la muestra presentó tártaro, siendo las mujeres aquellas más propicias a desarrollar este tipo de problema.

Durante el proceso de formación de la corona de los dientes puede ocurrir una amelogénesis imperfecta, atribuida a etapas de mala nutrición y de enfermedades durante la infancia (Wing y Brown 1979). Este fenómeno se manifiesta como surcos e irregularidades en la superficie del esmalte, y es conocida como "hipoplasia del esmalte". En esta población encontramos cinco individuos adultos afectados por esto, lo que representa el $10.6 \%$ del total de la misma.

Cambios degenerativos. El $66.7 \%$ de los adultos presenta alteraciones en la columna vertebral, siendo las vértebras lumbares las más afectadas, con un $60.6 \%$; las dorsales tienen un porcentaje de $51.5 \%$ y las cervicales apenas de un $21.2 \%$. Si bien hay un mayor número de mujeres con espondilosis $(n=14)$, son los hombres los que presentan el más alto grado promedio de desarrollo osteofítico. Ya entre los 35-40 años la casi totalidad masculina se presenta con el grado máximo.

De los 33 adultos examinados, el $60.6 \%$ presenta osteofitos en los codos; $27.3 \%$ en los tobillos; el $24.2 \%$ en las muñecas y el $9.1 \%$ en las rodillas y caderas. En la edad adulta, ya el $50 \%$ de la población muestra osteofitosis poco desarrollada en los codos, pero a partir de los 30 años, el 100\% de los individuos ya la presenta. Hay un leve predominio femenino.
Del total de nuestro análisis podemos inferir que el esfuerzo máximo en las actividades diarias era hecho por la columna en la región lumbar, y que los hombres hacían un esfuerzo más grande que las mujeres. No pudimos, entretanto, hacer inferencias en cuanto a la división de trabajos por sexos, porque ambos grupos presentan porcentajes cercanos de afección artrítica, en las mismas articulaciones; las diferencias se advierten en los grados de desarrollo en los osteofitos.

Línea de Harris. En esta población se advierte que 29 de los 46 individuos presentaron líneas de Harris, alcanzando un $63 \%$ de ocurrencias; el promedio de líneas por persona es de seis. Considerando los grupos sexuales por separado, hay una coincidencia plena en los porcentajes de ocurrencia, de $63.3 \%$ para cada uno. Los subadultos presentan el $61.5 \%$, ligeramente inferior a los adultos. A pesar de que la remodelación ósea más intensa en los hombres tiende a borrar las líneas radiopacas, son los hombres que muestran un mayor promedio de líneas: 7.9 por persona; las mujeres tienen 6.3 y los niños 3.8.

Espongio hiperostosis. Varios de los cráneos de esta población presentan una superficie ósea cribada por pequeños poros a lo largo de las suturas lambdoídea y sagital. Hemos quedado en duda si ello podría deberse a la hiperostosis o no. Varios especialistas consultados manifestaron dudas semejantes.

En definitiva, tenemos un cráneo infantil con criba orbitaria acentuada; muestra también pequeños poros a lo largo de las suturas lambdoídea y sagital.

Por ahora nos inclinamos a pensar en que dentro de este grupo se manifiesta una hiperostosis esbozada, posiblemente debida a una dieta limítrofe, con alternancias de períodos de abundancia y escasez, si no cuantitativa, por lo menos cualitativamente.

Traumas óseos. Encontramos ocho esqueletos adultos (24.2\% del total) con evidencias de fracturas. Son más frecuentes las de las muñecas, con el $15.1 \%$ de los casos. Estas son las fracturas típicas de una caída, cuando la persona trata de soportar el peso del cuerpo con las manos. Tenemos aún dos cráneos con hundimiento cicatrizado de la tabla externa; uno más con fractura consolidada del zigomático izquierdo y otro con fractura nasal. Estos casos de violencia representan el $12.1 \%$, cifra algo inferior a los $14 \%$ propuestos por Munizaga (1974) para la etapa tardía de San Pedro de Atacama. 


\section{Discusión}

En términos de estatus social no logramos vislumbrar una intención claramente discriminatoria en este cementerio. Ambos sexos y todas las fajas etarias comparten el espacio del sitio, en cuanto a tratamientos de enterramientos y de contextos ofrendados. Lo mismo sucede con los tipos de deformación craneana.

En relación a la cerámica se observa que no hay una relación directa entre los diferentes tipos y formas con los individuos, separados por edad o por sexo.

Si consideramos las bandas de plata como indicadores de estatus social, tenemos un adulto asociado con una de ellas; su ajuar, a pesar de ser abundante (11 piezas) no es el más numeroso ni el más rico. No presenta cerámica y la única calabaza no tiene decoración. Sólo la banda de plata singulariza el enterratorio de este individuo, en cuanto a contexto material. La otra distinción es la presencia de un niño, quien, aparentemente, fue enterrado después del sepultamiento del adulto, antes referido. La otra banda de plata se encontró con un niño de cuatro años.

Sin embargo, llama la atención la tumba de un subadulto de 10 años, cuyo ajuar señalaría un estatus especial dentro del grupo, tanto por la cantidad de piezas (14) como por la naturaleza de las mismas y la calidad de su elaboración. Cabe destacar que las vasijas foráneas encontradas entre sus ofrendas podrían ser la clave para una explicación que intentaremos más adelante.

En suma, en términos generales, pensamos que el espacio del cementerio fue usado sin ninguna intención de sectorización en cuanto a sexo, edad o posición social. Por lo anterior podríamos proponer tres situaciones:

a) Se trataría de una sociedad globalmente igualitaria, lo cual no concuerda con el desarrollo alcanzado en esta época por los señoríos locales.

b) Sería una sociedad socialmente estratificada, pero económicamente más igualitaria; esta posibilidad aparece también como remota en sociedades tardías de la zona.

c) Los señores locales fueron enterrados en otros cementerios o en otros sectores dedicados a clases sociales más jerárquicas.
Por ahora estas proposiciones sólo señalan que estamos frente a una situación poco documentada que merece mayor investigación.

Otra de las hipótesis que nos planteamos para Quitor 6 fue la identificación de un conjunto de cambios culturales verificado en los últimos tiempos de la Cultura San Pedro, acompañado de un "empobrecimiento" de las ofrendas funerarias, traducido en un desmejoramiento verificado tanto en la calidad como en la cantidad de objetos de los ritos de funebria. Estos hechos ya habían sido observados anteriormente por otros autores (Le Paige Ms Tarragó 1968).

Estos postulados los hemos contrastado en este estudio en donde precisamente advertimos que sí ocurrieron algunos cambios sustantivos. En efecto, al contabilizar las evidencias de alimentos, cordelería, etc., en los contextos de las tumbas del sitio, encontramos grosso modo, una sumatoria de 350 objetos, lo que da un promedio de 8.33 piezas por tumba. En dos oportunidades encontramos solamente una o dos especies alimenticias (maíz, algarrobo o chañar) y/o patas de camélidos. En otras dos o tres tumbas, además de estas evidencias, apenas un cesto o una calabaza se agregan al contexto. Esto contrasta fuertemente con la abundancia de los ajuares de las tumbas de la Fase Media de San Pedro de Atacama.

Por otra parte, el cambio ocurrido en la tecnología cerámica es otro indicador de nuevas modificaciones. Durante la Fase Media, la cerámica Negra Pulida alcanza un alto nivel técnico y una gran variedad de formas. Tarragó (1976) considera esta alfarería como evidentemente funeraria; ello implicaría una alta incidencia en las ofrendas funerarias. De las 2347 vasijas estudiadas por ella, el $82.20 \%$ corresponde al tipo Negro Pulido; el 11.84\% al Rojo Pulido y el $3.66 \%$ al Gris Grueso Pulido. En el supuesto de que el primer tipo fuera esencialmente funerario, se explicaría esta concentración en los contextos clásicos de San Pedro; a la duración diferenciada de las tradiciones culturales del área correspondería concentraciones también diferentes de las cerámicas características de cada tradición, y esto podría ser otra explicación viable. Nosotros acrecentamos el hecho de que el mayor énfasis, durante los años de trabajo de Le Paige, fue puesto en los cementerios de la Fase Media; por ello, la mayor cantidad de contextos de ese tiempo, y por ende, de la clásicacerámica Negra Pulida; sin embargo, a pesar de todo, no creemos que la intensificación de los 
estudios sobre otras fases de la cultura San Pedro venga a modificar sustancialmente este panorama. Verdaderamente, la artesanía cerámica de la Fase Media estuvo fuertemente desarrollada, con una producción de óptimo nivel técnico clásico y formal que persistió por largo tiempo.

En Quitor 6 a la par del bajo promedio de cerámica en los contextos (0.64 vasijas/tumba), encontramos una tecnología notoriamente inferior a la ya mencionada de la fase anterior. Contrastando con las vasijas de paredes delgadas, profundo color negro parejo (logrado a través de un perfecto control de la cocción), y sus atractivas y variadas formas de un bruñido intenso, la cerámica de Quitor 6 presenta rasgos más domésticos o de uso cotidiano con paredes gruesas, formas utilitarias y cocción dispareja. Difícilmente ambas superficies se encuentran pulidas; lo más corriente es que una sea alisada simplemente y la otra pulida, posiblemente con un carácter más funcional como lo señala Tarragó (1968). En otras oportunidades, ambas superficies presentan nada más que un alisado, algunas veces mejor realizado que en otras de la misma época tardía.

El color es variable, tal como se observa en el tipo Dupont (Núñez 1965) en donde el color negro es, si no perfecto, por lo menos bien logrado, lo que indica la posesión de la técnica de cocción reductora todavía en este tiempo. Asimismo, encontramos unos cuantos ejemplares del San Pedro Rojo Borravino (Tarragó 1976), donde también se advierte que los artesanos manejaban adecuadamente la cocción a fuego abierto. Pero, en los demás tipos, las zonas obscuras se presentan con tal frecuencia y extensión que se hace difícil determinar el color predominante en la pieza.

Llama la atención, además, que priman los recipientes más bien pequeños como platos y pucos bajos; las formas más grandes (sólo dos), tal vez podríamos relacionarlas a funciones de cocción de alimentos, aunque no encontramos evidencias claras de que hayan sido expuestas al fuego.

Lo observado en este contexto cerámico concuerda con lo afirmado por Tarragó: a) la mayor proporción y regularidad en los registros de esta cerámica se verifica en los sectores de sitios donde no se da ninguna tumba con Negro Pulido; b) "en todos los sitios es siempre mayor el número de tumbas sin ninguna especie cerámica" (Tarragó 1968: 133); c) la ocurrencia de tumbas "prácticamente sin ajuar funerario o reducido éste, a uno o dos elementos tales como: ganchos, espinas, etc." (Tarragó 1968: 133). Estas observaciones conducen a una reflexión sobre las causas del fenómeno. Estas podrían ser:

1) "Empobrecimiento" o simplificación general del desarrollo cultural: se seguía colocando junto al muerto sus pertenencias, como en tiempos pasados, pero éstas ahora eran escasas y poco elaboradas.

2) Cambios en la naturaleza de los ritos funerarios de la comunidad: ya no se elaboraban objetos mortuorios, como habría sucedido con la cerámica Negra Pulida, sino que se ofrendaban algunos de los objetos de uso cotidiano.

Como corolario surge otra hipótesis de trabajo, puesto que una vez determinada la existencia de estos cambios, debería identificarse las razones de su ocurrencia. Consideramos como posibles causas:

1) Pérdida de contacto de la Fase Tardía de la Cultura de San Pedro con las culturas vecinas, especialmente, las del área del altiplano nuclear (región del Titicaca).

2) Cambio de población en el marco de la distribución demográfica local.

3) Empobrecimiento de recursos en el territorio circumpuneño. En relación al primer punto, que las relaciones con otras subáreas culturales se mantienen vigentes en esta fase queda evidenciado en la cerámica. Una cerámica Roja Violácea con forma de "jarro-pato" muestra, en la parte posterior a la cola de pato estilizada, una decoración antropomorfa y ojos "grano de café" y nariz modelada (Figura 6, Forma VII); esta decoración es muy similar a la encontrada en vasijas del mismo tipo en Pica-1, norte de Chile (Latcham 1928: Lám. XXVII). Allí, las formas de este tipo cerámico son más alargadas que la que encontramos aquí, pero la decoración de ojos "grano de café" es muy parecida (L. Núñez com. pers.). Los tipos de utensilios en forma de "doble-salero" (Forma V), así como el tipo cerámica Dupont, también son encontrados en Pica 8 (L. Núñez com. pers.). Como testimonio de alguna forma de relación con el noroeste argentino, podría estar la Forma IV vinculada con La Isla, Quebrada de Humahuaca (Tarragó 1977). Con respecto al vasito de forma ovoide erecta cuello cilíndrico, inflexionado y restringido independiente, con decoración negro sobre rojo amarillento (Figura 6b), comparándolo 
con las descripciones de Posnansky (1896), pensamos que podría ser oriundo del sur de Bolivia. Esta última forma se encontraba juntamente con el "jarro-pato" formando parte del ajuar más numeroso del sitio, en la tumba de un niño de 10 años, al que nos referiremos más adelante.

Lo que sí queda definido es que estos contactos con otras comunidades tardías no se traducen en influencias sobre la población local tal como ocurrió durante la influencia Tiwanaku.

Para identificar posibles evidencias de cambio poblacional, tratamos de comparar nuestros datos biológicos con los de Le Paige (1961) y su descripción de 374 cráneos de diferentes sitios de San Pedro de Atacama. Le Paige no los asigna a ninguna cronología determinada, pero, conociendo que sus trabajos de campo se centraron preferentemente en los cementerios de la Fase Media, suponemos que estos cráneos pertenecen a esa fase. Tenemos así, el siguiente cuadro:

\begin{tabular}{|l|c|c|}
\hline \multicolumn{1}{|c|}{ Tipo de cráneo } & Le Paige & Quitor 6 \\
\hline hiperbraquicráneo & $29 \%$ & $30 \%$ \\
braquicráneo & $54 \%$ & $60 \%$ \\
mesocráneo & $15.6 \%$ & $10 \%$ \\
dolicocráneo & $1.4 \%$ & - \\
\hline
\end{tabular}

Cuadro 4. Tipos de cráneos.

Según este análisis, la población tardía difiere muy poco de las más tempranas de San Pedro de Atacama. Entretanto, esta conclusión está lejos de ser definitiva, por la naturaleza algo incierta de los antecedentes de Le Paige de que disponemos al momento.

Por otro lado, Munizaga (1969) señala un porcentaje de $79.6 \%$ de cráneos deformados pertenecientes a la Fase Tardía de la Cultura San Pedro, siendo la deformación más frecuente la Tabular erecta, con $70 \%$ de las ocurrencias. El porcentaje de cráneos deformados que encontramos es de $58.8 \%$ siendo la deformación frontoccipital (tabular oblicua) la más recurrente, con $40 \%$ de los casos. En una publicación posterior (Bittman 1978) hay una actualización de sus datos, indicando que al final de la Fase Tardía habría un resurgimiento del tipo tabular oblicuo, coexistiendo con la tabular erecta hasta la llegada de los españoles. En este sentido hemos verificado que esa coexistencia es cierta, ya que la deformación lambdoidal (tabular erecta) está presente en $25 \%$ de los casos.
Este resurgimiento de la deformación frontoccipital involucra una interrogante: ¿se retomaron las viejas prácticas deformatorias usadas durante la Fase II, o se reintrodujeron a través de una nueva población instalada en la región?

Los estudios de Soto (1975) dan cuenta de rasgos de variación discontinua para la población de la Fase Media de Quitor 6. Comparando sus datos con los nuestros, encontramos algunas diferencias importantes. La más destacada se refiere a las impresiones dejadas por la división arterial de los vasos supraorbitarios antes, o en el momento en que ellos dejan la órbita para seguir su camino hacia la cara externa del hueso frontal: habría un porcentaje de $24.39 \%$ para la Fase II, y $44.8 \%$ para la Tardía. Se advierte una importante diferencia también en cuanto a los surcos del frontal, con $75.38 \%$ para la Fase II y $58.62 \%$ para la Fase III. En cuanto al conducto lateral, la diferencia es mínima: $3.37 \%$ y $3.44 \%$, respectivamente.

En un trabajo reciente, Munizaga (1984) publica los resultados de un análisis comparativo entre poblaciones de las fases culturales de San Pedro de Atacama. De acuerdo a los mismos, se verifica una diferencia, en cuanto a los rasgos continuos, entre la población con cerámica Negra Pulida y las posteriores (con Negro Casi Pulido y Rojo Violáceo); esto vendría a apoyar nuestra suposición de un cambio poblacional en las fases más tardías. Pero advertimos que hay una discrepancia entre la información arrojada por los rasgos discontinuos de su trabajo y la nuestra: en el primer caso, las tres poblaciones serían muy similares, mientras que en nuestra comparación, se observan diferencias marcadas entre la gente de la Fase Tardía y las anteriores.

Hacemos notar que la presente comparación deberá ser revisada más prolijamente, pero hasta el momento de la realización de este trabajo, éstos eran los únicos datos disponibles para discutir un cambio poblacional entre ambas fases culturales del área.

Con referencia al tercer punto, donde se supone un posible empobrecimiento de recursos locales, disponemos de las siguientes consideraciones.

Hemos señalado el registro de cierta cantidad de maíz en las tumbas. Este recurso vegetal tan apreciado como componente de la dieta circumpuneña no se cultivó en todos los climas de altura, y aquellos grupos que lo producían, generalmente lo hacían a 
nivel de excedentes y ese maíz se constituía en un bien de trueque, recepcionado por las comunidades carentes de este recurso. Lo mismo pudo suceder con el algarrobo y el chañar, para consumo humano y bebidas alcohólicas. Podríamos postular que esta población tardía obtenía ciertos objetos foráneos sobre la base de trueque económico. No obstante estos datos son insuficientes puesto que igualmente podría tratarse de un intercambio de tipo ritualístico, un aprovechamiento vertical de otro ambiente ecológico por habitantes de esta zona a modo de colonias, o aun, el resultado de una migración, esporádica o no.

La biotipología del individuo enterrado junto con la cerámica foránea (ver Figura 5) no es concluyente, pues se trata de un sujeto muy joven; lo único que lo distingue de los demás es la calidad de su dentadura. Apenas dos de sus dientes presentan caries mínimas. Esto podría atribuirse a un tipo diferente de dieta: hay que tomar en cuenta que sus huesos largos no presentan líneas de Harris, significando ausencia de enfermedades importantes o de períodos de mala nutrición. Estos signos, más las características de su ajuar, podrían estar indicando el traslado de este niño desde otro ambiente hasta este lugar, muriendo aquí poco tiempo después de su arribo. Esta suposición se apoya en que, aparentemente, no hubo tiempo para que la ingestión de carbohidratos provocara el desarrollo de caries en los grados y en las cantidades encontrados en la demás gente local. Estos hechos podrían estar indicando, además, el cambio de su dieta anterior, hacia una basada más fuertemente en carbohidratos, cuando se iniciaron las caries, pero no todavía, la desnutrición.

Habría aún otra explicación. En la Revisita de Alonso Espejo, realizada en 1683 (Hidalgo 1983), hay un dato que señala que los atacameños se iban a las provincias vecinas a trabajar, con el fin de poder pagar las tasas impuestas por el orden administrativo. Un 33.33\% de ellos emigró, dejando en San Pedro (Atacama La Baja) a sus mujeres o a algunos de sus hijos. Sólo un $14.29 \%$ de estos tributarios ausentes se había casado con forasteras; ello implica que el vínculo con la tierra natal estaba presente y fuerte todavía, durante la colonia. Aún según Hidalgo (1983), la mayoría de los lugares mencionados en la Revisita de 1792 como residencia de los tributarios ausentes coincide con sitios arqueológicos del Período Medio y Tardío del Noroeste Argentino. Del mismo autor (1983: 4) tenemos el siguiente dato: "Atacama la Alta comprendía, además de los poblados cercanos, algunos otros en lo que hoy es la Puna argentina, como Susques e Incahuasi”. Conociendo además, el fuerte contacto mantenido por las poblaciones de San Pedro de Atacama con las zonas vecinas (Argentina y Bolivia), podemos inferir un patrón de movilidad de la gente de San Pedro entre esta localidad y las vecinas, aunque no podemos precisar la naturaleza de la misma. ¿Se trataría de enclaves ecológicos de uso estacional, del régimen de colonias, o de flujo migracional?

En un trabajo de Arellano (1981: 57) encontramos más información sobre este problema. El autor cita a Lozano Machuca (1581) cuando indica que los indígenas de la región de Lípez mantenían contacto con la gente de Potosí, Tarapacá y Atacama, y posiblemente Talina y Tarija. Los estudios arqueológicos actuales realizados en Bolivia (Arellano 1981) coinciden con lo que expresan los cronistas, en el sentido de que "muchos de los productos de consumo o bienes de uso incorporados a la vida cultural del altiplano procedían de lugares más bajos”, y serían cambiados por minerales, cuero, lanas, sal, etc. Núñez (1975: 18) duda de la instalación de colonias, pero considera que "al rescatar producciones fuera del altiplano, pudieron realizar explotaciones directamente, intercambiando a la vez sus excedentes ganaderos y mineros". Se trata aquí de una eventual consignación de las prácticas de trueque con instalaciones de colonias lo que, consideramos, ratifica nuestros criterios de apreciación, pero este tema merece aún una mayor atención.

Podríamos aceptar tentativamente que esta comunidad atacameña aprovecharía en alguna forma, nichos ecológicos ubicados en el altiplano boliviano y en la puna argentina, siguiendo un patrón según el cual se ausentaba preferentemente el hombre, quedando la mujer y los hijos en su lugar de origen, lo que explicaría el bajo número de hombres presentes en el sector tardío del cementerio Quitor 6.

Existen algunas inferencias sobre la dieta de esta población que podríamos tratar de hacer, basándose en la información arrojada por el análisis biocultural. La alimentación de un grupo humano con una economía agrícola pastoril, es de esperarse que fuera equilibrada, en cuanto a la ingestión de carbohidratos y de proteínas de origen animal. Pero vemos que, en la población que nos ocupa, pareciera haber un desbalance en favor de los carbohidratos. Analizando la patología bucal (cantidad y tipos de caries, enfermedades peridontales), todo habla en favor de una 
dieta blanda, rica en carbohidratos, como lo es el maíz. Esta suposición se fortalece en las evidencias encontradas en las tumbas, consistentes en mazorcas y granos de maíz, así como de fragmentos de caña de la planta, con los complementos nutrientes de los frutos de algarrobo y chañar. Aparentemente, el rol de los productos cárneos no fue significativo, pero el recurso animal no se encuentra ausente, aunque no tenemos los medios para evaluar su importancia como alimento dominante o no. Las evidencias de llamas están en los contextos pero sólo podemos señalar que se consumieron sin calificar su importancia. Nos faltan los basurales con muestras más concluyentes como la del faenamiento de animales y, sobre todo, restos óseos que nos indiquen la cantidad de animales sacrificados. En la patología bucal encontramos un indicador que tal vez pudiera aclarar este punto, y es el tártaro presente en los dientes. Sin embargo, aquí encontramos una aparente contradicción que no podemos resolver: según el teórico (Hillson 1979), las caries se producen por pérdida del mineral del esmalte dentario, causada por la acción del ácido láctico que, a su vez, es producido a partir de la metabolización de los azúcares presentes en los carbohidratos. El tártaro, por el contrario, es consecuencia de la reposición en demasía de sustancia mineral desde el stock que se mantiene en suspensión en la saliva. Así, habiendo un largo período de ingestión de carbohidratos, se originan las caries; en cambio, si la ingestión de proteínas es mantenida por mucho tiempo, aparece el tártaro.

Entre los individuos adultos de Quitor 6 encontramos que $84.8 \%$ presenta caries y $30.3 \%$ tártaro. $^{4}$ Esto estaría confirmando el supuesto de una dieta basada en los carbohidratos. Sólo tendríamos que señalar que, en los individuos portadores de tártaro, también se observan caries.

Verificamos también la existencia de una situación de espongio hiperostosis esbozada, que atribuimos a una dieta limítrofe, con alternancias de períodos de escasez con los de abundancia, aunque no podríamos precisar si se trata de un problema cuantitativo o cualitativo suficientemente representativo.

4 Considerando la calidad del agua de la zona, con altos contenidos de minerales disueltos, creemos que su aporte debió ser importante en la formación de tártaro.
Asimismo, se registra la ocurrencia de amelogénesis imperfecta (hipoplasia del esmalte) en un $10.6 \%$ de la población; este fenómeno se debe a: los efectos de una dieta desbalanceada; la carencia de vitamina D; y/o estados febriles en las enfermedades.

En relación a las líneas de Harris, los estudios de Park $(1954,1964)$ y de Park y Richter $(1953$, en Wing y Brown 1979) indican que las mismas serían ocasionadas por la combinación de dos procesos: la depositación de materia ósea cuando, por restricciones dietéticas, se detiene el crecimiento del cartílago de las epífisis pero no la actividad de los osteoblastos y, luego, cuando la nutrición adecuada es retomada, una nueva carnada ósea se deposita sobre la primera, por la recuperación de las células cartilaginosas. Este segundo estrato es llamado "factor de recuperación" (recovery factor). De ser así, para la existencia de la línea de Harris sería necesario, no solamente un período de mala nutrición, sino que éste debería ser seguido por otro período de nutrición adecuada.

Nuevamente sentimos la falta de excavaciones en sitios de vivienda y/o basurales. Definitivamente no sabemos bien qué está pasando en la dieta de este grupo humano o si existe un optimum de producción de alimentos o no en esta etapa cultural.

Pensamos que lo discutido anteriormente sobre la movilidad de las poblaciones en esta fase (ciertamente fuera de los moldes coloniales que encontramos en las Revisitas), tendría que estar sujeta a condiciones que fueran favorables a la comunidad. Dicho de otra manera, el grupo familiar o el hombre que sale de su ayllu, lo hace temporalmente, para conseguir elementos que no se dan aquí, pero vuelve en las épocas críticas de siembra y de cosecha. Y es lícito pensar que, a su regreso trae productos logrados en otros nichos ecológicos.

Este planteamiento debilita la hipótesis de una posible baja en la producción de alimentos por causa de dicha movilidad, en San Pedro de Atacama.

Aún en el caso de que hubiese una escasez de granos al final del invierno, y durante los 90 días que tarda el maíz en producir, la presencia del ganado, roedores, aves y cultígenos embodegados prevendría la hambruna; posiblemente sólo quedarían evidencias del cambio de dieta en la dentadura (caries vs. tártaro). Tal análisis deberá realizarse como consecuencia de estas hipótesis aún en proceso de contrastación. 
Sin embargo, no nos queda más que especular: por alguna razón no sospechada todavía, la producción de alimentos durante la Fase Tardía en Quitor 6 era, temporalmente, inferior a las necesidades del grupo humano que ahí vivía, redundando en una dieta críticamente limítrofe.

\section{Conclusiones preliminares}

Después de determinar las características culturales de la Fase Tardía, y de la comparación que realizamos entre esas características y la de la Fase Media, es evidente que ha ocurrido aquí un fuerte cambio cultural, evidenciado por:

a) Los nuevos patrones de depositación del cuerpo en las fosas funerarias.

b) Los nuevos patrones de enterratorios.

c) La cantidad menor de ofrendas y de ajuar asociados al enterratorio.

d) La calidad menor de la elaboración de los objetos pertenecientes al contexto funerario.

e) Los nuevos tipos cerámicos.

f) La baja frecuencia de las vasijas cerámicas en las tumbas.

g) El tamaño menor de dichas vasijas; h) los tejidos más simplificados.

En suma, las características culturales de la Fase Tardía del cementerio Quitor 6 son notablemente diferentes a aquéllas propias de la Fase Media.

Del análisis de los materiales queda en evidencia el hecho de que el número de piezas que componen los ajuares y ofrendas de las tumbas es considerablemente inferior al encontrado en los enterratorios de la Fase Media; asimismo, toda la rica decoración presente en tejidos, calabazas y cestería, así como el esmerado tratamiento de la cerámica, ha desaparecido casi totalmente en los últimos tiempos de la Cultura San Pedro. Lo anterior se puede traducir como un "empobrecimiento" cultural.

De ese análisis se desprende también que el contacto con el altiplano nuclear y meridional sigue vigente hasta los tiempos tardíos de esta cultura, sin que podamos saber cuál era su naturaleza y la intensidad del mismo. Lo que sí queda definido es que no ejerce una influencia notable sobre la población local en el mismo grado en que lo hacía Tiwanaku. Las relaciones también se verifican con el Complejo Pica Tarapacá y posiblemente con los del Noroeste Argentino. La consulta a las fuentes etnohistóricas pareciera apoyar esta suposición de contactos interregionales.

La evidencia antropológico-física nos muestra que la población de la Fase Tardía de la Cultura San Pedro, en el sitio de Quitor 6, era aparentemente semejante a la de la Fase II, en cuanto a los índices craneométricos. Entretanto, las deformaciones craneanas nos entregan una información novedosa: la práctica de la deformación frontoccipital (tabular oblicua) vuelve a ser la más frecuente, señalando la posibilidad de un cambio poblacional. Esto se ve reforzada por el dato de los rasgos de variación discontinua que nos estaría indicando ser ésta una población genéticamente diferente a la de la Fase Media.

El "empobrecimiento" de recursos económicos, y las causas del desmejoramiento cultural es difícil de ser probado, en el actual estado de las investigaciones. Hacemos hincapié en la falta de registros en sitios de viviendas para aclarar este punto. Es evidente que la población tenía problemas de salud y/o nutrición. Entretanto, no tenemos la información comparativa con poblaciones de las fases anteriores, lo que nos imposibilita afirmar o no un deterioro sustantivo del estado nutricional, que pudiera sugerirnos un cambio en los recursos de subsistencia.

Postulamos tentativamente que el cambio cultural verificado en esta zona se debe a un cambio y/o recomposición de la población local, más que a alteraciones en los intercambios culturales con otras regiones, $\mathrm{o}$ de un empobrecimiento económico local.

\section{Resumen final}

La población que ocupó el sector norte del cementerio Quitor 6, entre 940 y 1240 DC, se trataría de un grupo que habría total o parcialmente arribado a esta zona en algún momento final de la Fase Media de la Cultura San Pedro, con una economía de tipo agropastoril. Tendría contactos con nichos ecológicos de otras regiones vecinas, como los oasis piemontanos (Pica), el Altiplano Meridional boliviano, valles y oasis del Noroeste Argentino, en un patrón de movilidad que no podemos determinar, por ahora. 
Sus características culturales son poco representativas en cuanto a la cantidad de los objetos encontrados en las tumbas. Su organización social era, aparentemente algo igualitaria, aunque algunos indicios nos hacen sospechar de una cierta diferenciación de estatus entre ellos (bandas de plata, uso de gorros). Pensando que en ese tiempo ya existía un "señorío" en Atacama, podría ser posible que en este cementerio estén ausentes los individuos pertenecientes a las clases de mayor jerarquía político-religiosa.
Físicamente esta población se define de baja estatura, con fuerte predominancia de cráneos redondos y bajos. Las caras tienden a ser medianas, las órbitas estrechas y altas,y las narices medianas. Hay un dimorfismo sexual poco acentuado. La consignación de datos biológicos y culturales es sugestiva y nos introduce a un análisis permanente con nuevos aportes en la medida que estas hipótesis se contrasten con nuevos datos y distintas clases de sitios.

\section{REFERENCIAS CITADAS}

ADOVASIO, J. M., 1977. Basketry technology. Aldine Publishing Co. Inc., Chicago.

ARELLANO, J., 1981. Mallku: Señorío post-Tiwanaku del Altiplano Sur de Bolivia (provincias Nor y Sur Lípez, Depto. de Potosí). Bulletin de L'Institut Français D'Etudes Andines X (1 y 2).

BASS, W. M., 1971. Human osteology: A laboratory and field manual of the human skeleton. Special Publications, Missouri Archaeological Society, Columbia.

BERENGUER, J., A. DEZA, A. ROMAN y A. LLAGOSTERA, 1986. La secuencia de Myriam Tarragó para San Pedro de Atacama: Un test por termoluminiscencia. Revista Chilena de Antropología 5.

BITTMAN, B., L. NUÑEZ y G. LE PAIGE, 1978. Cultura atacameña. Colección Culturas Aborígenes. Depto. de Extensión Cultural del Ministerio de Educación, Serie Patrimonio Cultural Chileno, Santiago.

CASTRO, M. y S. QUEVEDO, 1983-84. Proposiciones metodológicas para el estudio de los rasgos no-métricos en el cráneo humano. Boletín del Museo de Historia Natural de Chile 40.

CLARKE, J., 1965. Population Geography. Oxford University Press, Nueva York.

DROESSLER, J., 1981. Craniometry and biological distance. Center for American Archaeology. Northwestern University, Evanston.

ESPOUEYS, O., 1972-73. Tipificación de cucharas de madera de Arica. Actas del VI Congreso de Arqueología Chilena. Boletín de Prehistoria $\mathrm{n}^{\circ}$ especial. Universidad de Chile y Sociedad Chilena de Arqueología, Santiago.

FUNG, R., 1958-59. Pequeño glosario textil. Cuadernos del Centro de Estudiantes de Antropología 1 (3).

GILBERT, B. M. y T. W. MCKERN, 1973. A method for aging the female os pubis. American Journal of Physical Anthropology 38 (1).
HIDALGO, J., 1983. Complementariedad ecológica y tributo en Atacama: 1683-1792. Paper prepared in advance for participants in symposium 91 . "An interdisciplinary perspective on Andean ecological complementarity", Cedar Cover, Cedar Key.

HILLSON. S., 1979. Diet and dental disease. World Archaeology II (2).

LATCHAM, R., 1928. La alfarería indígena chilena. Santiago.

LE PAIGE, G., 1961. Estudio craneométrico de la colección del Museo Arqueológico de San Pedro de Atacama. Anales de la Universidad del Norte año 1 (1), Antofagasta.

- Ms. Manuscritos de terreno. Archivo del Instituto de Investigaciones Arqueológicas de San Pedro de Atacama, Universidad del Norte, San Pedro de Atacama.

LOVEJOY, C. OWEN, R. S. MEINDL, T. R. PRYZBECK, R. P. MENSFORTH, 1985. Chronological metamorphosis of the auricular surface of the Ilium: A new method for the determination of adult skeletal age at death. American Journal of Physical Anthropology 68 (1).

McKERN, T. W. y S. D. STEWART, 1957. Skeletal age changes in young males. Head quarters, quartermaster research and development command. Technical Report EP-45, Natick.

MEINDL, R. y C. O. LOVEJOY, 1985. Ectocranial suture closure: A revised method for the determination of skeletal age at death based on the lateral-anterior sutures. American Journal of Physical Anthropology 68 (1).

MEINDL, R., C. O. LOVEJOY y R. P. MENSFORTH, 1985. A revised method of age determination using the Os Pubis, with a review and tests of accuracy of other current methods of pubic symphyseal ring. American Journal of Physical Anthropology 68 (1).

MOLNAR, S., 1972. Tooth wear and culture: a survey of tooth functions. Current Anthropology 13 (5).

MUNIZAGA, J., 1969. Deformación craneana intencional en San Pedro de Atacama. Actas del V Congreso Nacional 
de Arqueología. Museo Arqueológico de La Serena, La Serena.

1974. Paleopatología chilena (informe preliminar). Antropología, Nueva Epoca 7.

1984. Poblaciones atacameñas: Aspectos morfológicos. Actas del XLIV Congreso Internacional de Americanistas, Simposio Culturas Atacameñas. Universidad del Norte, San Pedro de Atacama.

NUÑEZ, L., 1963. Los keros del norte de Chile. Antropología año I, I (1).

1964. Influencia de Tiahuanaco en la talla en madera del norte de Chile. Boletín de la Universidad de Chile 50.

1965. Desarrollo cultural prehispánico del norte de Chile. Estudios Arqueológicos 1.

1976. Registro regional de fechas radiocarbónicas del norte de Chile. Estudios Atacameños 4.

NUÑEZ, L., V. ZLATAR y P. NUÑEZ, 1975. Relaciones prehistóricas trasandinas entre el Noroeste Argentino y norte chileno (Período Cerámico). Serie Documentos de Trabajo 6. Universidad de Chile, Antofagasta.

POSNANSKY, A., 1896. Tihuanacu. La cuna del hombre americano. Ministerio de Educación, La Paz.
SOTO, P., F. ROTHHAMMER, C. VALENZUELA, E. LLOP y Z. HARB, 1975. Aplicación de un método de distancia genética en la comparación de poblaciones prehispánicas de América. Chungara 5.

TARRAGO, M., 1968. Secuencias culturales de la etapa agroalfarera de San Pedro de Atacama. $37^{\circ}$ Congreso Internacional de Americanistas, vol. 2. Buenos Aires.

1976. Alfarería típica de San Pedro de Atacama. Estudios Atacameños 4.

1977. Relaciones prehispánicas entre San Pedro de Atacama (norte de Chile) y regiones aledañas: Quebrada de Humahuaca. Estudios Atacameños 5.

TROTTER, M. y G. GLESSER, 1958. A pre-evaluation of estimation of stature based on measurements of stature taken during life and of long bones after death. American Journal of Physical Anthropology 16 (1).

UBELAKER, D. H., 1978. Human skeletal remains: Excavation, analysis and interpretation. Aldine Publishing Company, Chicago.

VALLOIS, H. V., 1965. Anthropometric techniques. Current Anthropolgy 6.

WING., E. y A. BROWN, 1979. Paleonutrition. Academic Press Inc. Studies in Archaeology, Nueva York. 